\title{
Fundamentos teóricos de la contabilidad del conocimiento y su incidencia en la auditoría del capital intelectual
}

\author{
CPC Miguel Nicolás Díaz InChicaqui
}

Docente de la Facultad de Ciencias Contables

\section{RESUMEN}

La investigación titulada: "Fundamentos Teóricos de la Contabilidad del Conocimiento y su Incidencia en la Auditoria del Capital Intelectual», analiza la problemática actual de la ciencia contable derivada de la globalización económica y cambios en los modelos de gestión empresarial en la cual prevalecen los activos inmateriales de la organización. Estos cambios han originado nuevos paradigmas contables que han afectado a nuestra ciencia en su metodología de determinación de la información financiera para la toma de decisiones y la valorización de empresas. Es decir, en el marco de esta nueva visión de la economía ha cobrado importancia una nueva concepción denominada: "el capital intelectual» que representa un desafio para la contabilidad tradicional al no contabilizarse actualmente este activo intangible.

Para abordar ésta problemática identificada, estamos convencidos que debemos hacer teoría de la teoría existente con la finalidad de adecuarla a esta nueva realidad. Para ello debemos de metateorizar la contabilidad del conocimiento, entendiendo el rol de la epistemología y la filosofía, en la evolución del pensamiento contable, la influencia de las tesis de Kuhn y los programas de investigación de Lakatos aplicados a la contabilidad entre otros.

Los fundamentos teóricos propuestos se basan en primer lugar, en el cambio en la visión y misión de la contabilidad, para ello es necesario aplicar el Enfoque Sistémico Integrado, que nos ayudará en la determinación de una nueva sintesis paradigmática que considere hechos no abordados por la contabilidad tradicional. Asimismo, derivado de este enfoque hemos determinado un contexto tetradimensional para la teorización de la contabilidad del conocimiento, aliándonos a través de una teoría convergente con las ciencias económicas y administrativas. Al final de nuestra investigación, planteamos un nuevo modelo contable, que identifica y valoriza los negocios empresariales con las nuevas variables denominadas: Potencialidad, performance $y$ posicionamiento empresarial, las cuales servirán para realizar la auditoria del capital intelectual.

Palabras clave: Epistemología, contabilidad, auditoría. 


\section{INTRODUCCIÓN}

La investigación titulada: «Fundamentos Teóricos de la Contabilidad del Conocimiento y su Incidencia en la Auditoría del Capital Intelectual», analiza los fundamentos teóricos de la ciencia contable, la evolución de su metodología, y la problemática de la medición de hechos que se suscitan en las organizaciones empresariales en la nueva economía del conocimiento.

La problemática actual de la ciencia contable se inicio cuando las organizaciones empresariales se dieron cuenta que la gestión de los negocios no debería basarse sólo en la gestión de activos tangibles que tradicionalmente creaban valor a los negocios desde la era industrial, sino que estas actualmente debieran considerar el despliegue de los activos inmateriales de la organización, tales como: relaciones con los clientes, productos y servicios innovadores, procesos operativos eficaces de alta calidad, tecnología de la información, bases de datos y las habilidades y motivaciones de los empleados, las cuales forman parte de la gestión estratégica de los negocios en la nueva economía del conocimiento.

En la economía actual que vivimos la ventaja competitiva de los negocios esta en la gestión de los intangibles o activos basados en el conocimiento. Es por ello, que los gestores necesitan de herramientas que describan estos activos y les ayude a implantar las estrategias de creación de valor ya que sin ella su gestión se dificulta al no poder identificarlos, describirlos ni medir dichos activos.

Es decir, en el marco de esta nueva visión de la economía ha cobrado importancia una nueva concepción denominada: «el capital intelectual» que representa un desafío para la ciencia contable que debe empezar a ser superado a nuestro entender con la revisión de la teoría del conocimiento contable las mismas que deben estar fundamentadas en la filosofía y epistemología, la evolución histórica de la contabilidad su metodología y las prácticas de exposición de la información.

Este desafío profesional es tomado en cuenta en esta investigación ya que aún no se ha divulgado de una manera masiva los aspectos conceptuales de la contabilidad del conocimiento, habiéndose considerado sólo las convenciones contables adaptadas y aprobadas en la NIC 38 «Intangibles» emitidas por la Contaduría Pública de la Nación. Al final de este trabajo presentamos nuestra propuesta de un nuevo modelo de visión de la contabilidad la cual la fundamentamos teóricamente considerando además su proceso de auditoría en el contexto de la nueva economía.

\section{LA TEORÍA DEL CONOCIMIENTO Y LA CONTABILIDAD}

\section{Nociones preliminares}

La investigación científica es un proceso que tiene como finalidad lograr un conocimiento ${ }^{1}$ objetivo, es decir, verdadero, sobre determinados aspectos de la realidad, a fin de utilizarlo para guiar la práctica transformadora de los hombres. La práctica científica ha demostrado que la investigación es un conjunto de procesos ligados por múltiples nexos que dan cuenta de su complejidad. Se encuentra en permanente desarrollo y transformación, y adopta múltiples aspectos y relaciones en un devenir histórico que no tiene punto final.

1 El fin del conocimiento estriba en alcanzar la verdad objetiva. 


\section{¿Metafísica o ciencia?}

El término de metafísica surgió en el siglo I a. n. e. para designar una parte de la herencia filosófica de Aristóteles y significa, literalmente, «lo que sigue después de la física». El propio Aristóteles había denominado a esta parte de su doctrina filosófica —en opinión suya, la más importante- «filosofía primera», que investiga los principios superiores de todo lo existente, a juicio de Aristóteles inaccesible a los órganos de los sentidos, comprensibles tan sólo intelectivamente y necesarios para todas las ciencias.

La idea de la metafísica como modo antidialéctico de pensar, como resultado de la unilateralidad y del subjetivismo en el conocimiento, como manera de ver las cosas y los fenómenos considerándolos acabados e invariables, independientes unos de otros, negando las contradicciones internas en calidad de fuente de desarrollo en la naturaleza y en la sociedad, surge en la Época Moderna.

Ello estaba condicionado históricamente por el hecho de que el conocimiento científico y filosófico al profundizarse y diferenciarse el saber científico, descompuso la naturaleza en varias esferas aisladas, vistas fuera de toda conexión entre ellas. Esto fue obra de Carlos Marx (1818-1882) y Federico Engels (18201895), quienes generalizando los datos de las ciencias y del desarrollo social, pusieron de manifiesto la inconsistencia científica del pensamiento metafísico y le contrapusieron el método de la dialéctica materialista.

La negación de los cambios cualitativos, la comprensión del desarrollo sólo como aumento o disminución cuantitativa, como una simple repetición de lo ya existente, sin nacimiento de algo nuevo, la renuncia a re- conocer las contradicciones internas como fuente del desarrollo, son también aspectos característicos de la metafísica de nuestros días. Pues, la Dialéctica es una ciencia que trata de las leyes más generales del desarrollo de la naturaleza, de la sociedad y del pensamiento humano.

La ciencia $^{2}$ es una forma de conciencia social; constituye un sistema, históricamente formado, de conocimientos ordenados cuya veracidad se comprueba y puntualiza constantemente en el curso de la práctica social. La fuerza del conocimiento radica en el carácter general, universal, necesario y objetivo de su veracidad. A diferencia del arte, que refleja el mundo valiéndose de imágenes artísticas, la ciencia lo aprehende en conceptos mediante los recursos del pensamiento. Frente a la religión, que ofrece una representación tergiversada y fantástica de la realidad, la ciencia formula sus conclusiones basándose en hechos, y no en deshechos. La realidad es, para la ciencia, el punto de partida y de llegada. Además, el conocimiento ${ }^{3}$ constituye un complejo proceso dialéctico que se efectúa en distintas formas, posee sus estadios y grados, y en él participan distintas fuerzas y aptitudes del hombre.

En tanto, que la filosofía es la ciencia sobre las leyes universales a que se hallan subordinados tanto del ser (es decir, la naturaleza y la sociedad) como el pensamiento del hombre, el proceso del conocimiento. Consecuentemente, la filosofía es una de las formas de la conciencia social y está determinada, en última instancia, por las relaciones económicas de la sociedad. La cuestión fundamental de la filosofía como conciencia especial estriba en el problema de la relación entre el pensar y el ser.

2 La ciencia por sí misma no existe; es un producto intelectual del hombre, es una descripción y explicación de todos los fenómenos que lo rodean.

3 Proceso en virtud del cual la realidad se refleja y reproduce en el pensamiento. 


\section{La teoría del conocimiento}

Preguntas: ¿Cómo es posible el conocimiento? ¿En qué se funda el conocimiento? etc., pertenecen a una disciplina filosófica llamada: «Teoría del conocimiento», «Crítica del conocimiento», "Gnoseología», «epistemología». Las preguntas antes formuladas, no obstante su generalidad, no agotan los problemas que se suscitan en la teoría del conocimiento. El problema - los problemas - del conocimiento ha sido tratado por casi todos los filósofos, pero la importancia que ha adquirido la teoría del conocimiento como «disciplina filosófica» es asunto relativamente reciente.

Los griegos introdujeron en la literatura filosófica, y con sentido preciso, los términos que nos sirven todavía para designar esta disciplina. Con frecuencia trataron problemas gnoseológicos, pero solían subordinarlos a cuestiones llamadas «ontológicas». La pregunta: ¿Qué es conocimiento? Algo parecido sucedió con muchos filósofos medievales. Sin embargo, es plausible sostener que sólo en la época moderna ${ }^{4}$ el problema del conocimiento se convierte a menudo en problema central — sí bien no único- en el pensamiento filosófico. La constante preocupación de los autores aludidos por la estructura del conocimiento es muy puntual. Pero todavía no se concebía el estudio del conocimiento como pudiendo dar impulso a una nueva disciplina filosófica. Desde Kant Immanuel (1724-1804), en cambio, el problema del conocimiento comenzó a ser objeto de la «teoría del conocimiento». Además, se ha manifestado con frecuencia en el pensamiento filosófico moderno y contemporáneo una cierta «epistemofilia», que contrasta con la «ontofilia» de los griegos y de los medievales. Es probable que, como ha indicado Nicolai Hartmann, los problemas gnoseológicos se hallen estrechamente co-implicados con problemas ontológicos.

\section{Origen del conocimiento 5}

A la interrogante ¿cuál es el origen del conocimiento? La cuestión del origen del conocimiento ${ }^{6}$ humano puede tener tanto un sentido psicológico como un sentido lógico.

El racionalismo (de ratio $=$ latín) ve en el pensamiento, en la razón, la fuente principal del conocimiento humano. Según él, un conocimiento sólo merece, en realidad, este nombre cuando es lógicamente necesario y universalmente válido.

El empirismo es una teoría epistemológica que considera que la experiencia sensorial como única fuente del saber; afirma que todo conocimiento se fundamenta en la experiencia y se adquiere a través de la experiencia.

Consecuentemente, la teoría del conocimiento es, como su nombre indica, una explicación e interpretación filosófica del conocimiento humano.

\section{Relación de la teoría del conocimiento y la contabilidad ${ }^{7}$}

Para hablar de la relación existente entre la teoría del conocimiento y la contabilidad en primer lugar debemos decir que el conoci-

4 Con varios autores renacentistas interesados por el método y con Descartes, Malenbrache, Leibniz, Locke, Berkeley, Hume y otros.

5 El origen de nuestro conocimiento está en el reconocimiento de las leyes objetivas de la naturaleza y del reflejo aproximadamente exacto de tales leyes en el cerebro del hombre.

6 Existen varias tesis: racionalismo, empirismo, intelectualismo, apriorismo, [...].

7 La contabilidad es una ciencia social, conjunto de conocimientos sistematizados que reflejan estructuras contables del proceso de producción de bienes y servicios (Juan Javier, León García: 1993). 
miento científico contemporáneo se dirige hacia la fría abstracción de la razón y de la materia, ya que vincula el pensamiento con la experiencia. No obstante ello, es importante que la verdadera dimensión constructiva del conocimiento humano deba ser analizada dentro del contexto de la filosofía y la epistemología, ya que estas categorías ayudan a mejorar los resultados de la investigación científica de una manera crítica y dialogada. Entonces en primera instancia, queda claro es que no se podría iniciar una metateorización de la contabilidad del conocimiento sin entender primero el rol de la epistemología e inclusive de la filosofía.

¿Pero qué tiene que ver la epistemología y la filosofía en la contabilidad?, para responder esta interrogante debemos de retroceder y analizar la historia del pensamiento contable, en ese caminar retrospectivo están el profesor Richard Mattessich que basa sus tradiciones de la investigación contable en la epistemología de Thomas Kuhn, aunque va más allá de este sistema cognitivo. Lo mismo podríamos decir de Leandro Canibaño quien construye sus programas de investigación contable dentro del contexto de la epistemología de Imre Lakatos. Es decir, con estos ejemplos lo que se quiere es justificar que la metateorización de la contabilidad del conocimiento previo análisis crítico filosófico y epistemológico.

\section{La filosofía y la epistemología en la teoría contable}

- La filosofía nos permite tener una visión crítica y discursiva del contexto, es decir, hace de nuestra razón un prototipo de realizar análisis de todos los problemas de nuestra realidad. Jesús Mosterín, reconocido filósofo español, dice que «Hoy día todos estamos bombardeados por una constante avalancha de información a través de la radio, televisión, los libros, las revistas, e Internet, etc. En todos estos medios se cuela cualquier cosa. Es importante que nuestras ideas sean lo más fiables, para lo cual tiene que haber una instancia crítica, un filtro. Esa instancia ese filtro es la filosofía».

Hoy en día vivimos bajo la influyente sociedad post-capitalista, en el que el liberalismo económico y su aliado la globalización económica han generado sociedades emergentes donde la «información base del conocimiento", es la piedra angular del desarrollo socio-económico. Este hecho determina que las sociedades se estén virtualizando en todos los ámbitos del contexto donde se desenvuelven las organizaciones empresariales. De esta virtualización, se vienen recibiendo recetas infalibles que realzan la realidad pero que necesitan justificarse a través de la Filosofía crítica para ingerir lo esencialmente verosímil.

- La epistemología, es la rama de la filosofía que estudia la investigación científica y su producto el conocimiento científico. En ese sentido podemos dividir la epistemología en tres aproximaciones policonceptuales: (i) Estudio crítico-filosófico de la ciencia, (ii) estudio de la constitución de conocimientos válidos y (iii) Estudio del paso de los estados de mínimo conocimiento a los estados de conocimiento más riguroso.

La epistemología es la disciplina autorreguladora del conocimiento científico. Las consideraciones expuestas nos abren un camino reflexivo en el ámbito contable porque nos hemos visto influenciados por algunas posturas epistemológicas engendrados a lo largo del período evolutivo del conocimiento contable. Entre 
estas posturas epistemológicas tenemos: Karl Popper con su teoría falsacionista, Thomas Kuhn con su epistemología histórica, Lakatos con sus programas de investigación y recientemente Bunge con su realismo crítico.

Resumiendo, diríamos que la teoría del conocimiento es una explicación e interpretación filosófica del conocimiento humano, que comprende algunas cuestiones fundamentales como: La posibilidad del conocimiento (es posible que el sujeto cognoscente pueda aprender del objeto) ¿hasta qué medida se puede lograr un conocimiento objetivo? De otro lado el origen del conocimiento, ¿cuáles son las fuentes de nuestro conocimiento? Explicadas tanto por el empirismo como por el racionalismo. Y por último, sobre el conocimiento verdadero, ¿cuál es el criterio para determinar si un conocimiento en verdadero o no?

Finalmente, indicaremos los beneficios que traería la epistemología dentro de la contabilidad:

- Dejar ser prisioneros de una doctrina incoherente, impuesta más allá de su racionalidad lógica por su carácter legal económico y social.

- Permitirá engendrar nuevos paradigmas y proyectos de investigación en forma continua; esto ensanchara la visión de la contabilidad, siguiendo el mismo proceso del método científico.

- Ampliará las líneas y programas de investigación contable, entrelazando nuevos métodos, técnicas y estrategias que permitan realizar investigación de alto nivel.

- Nos permitirá encontrar la racionalidad científica de la contabilidad, a través del análisis teórico y la reflexión epistemológica.
- Conllevara a una revisión dinámica, critica, discursiva y descriptiva de nuestra disciplina a través de su historia, a fin de resolver nuevos problemas.

- Nos acostumbrara a explicar sistemáticamente las conjeturas hipotéticas planteadas y por lo tanto, dejar de ser solamente máquinas receptivas y descriptivas.

- Le permitirá al contador dudar de los datos empíricos que salen de las teorías y de los marcos contextuales.

\section{EL DEVENIR HISTÓRICO DEL PENSAMIENTO CONTABLE}

La Contabilidad en sus orígenes "fue meramente empírica y respondía sólo a la necesidad de registro. Posteriormente a medida que ésta necesidad elemental va siendo satisfecha, se inició el proceso de investigación de principios y causas que caracterizan a la Ciencia, sometiéndose a sistematización el contenido del material poseído, buscándose generalizaciones, relaciones que dieron origen a los primeros principios». Fernández Pirla (1983)

Según el profesor Requena (1986), «resulta evidente que, aunque su origen parece situarse en las primeras manifestaciones mentales del control económico de las haciendas, ello no puede considerarse, en modo alguno, como ruptura constitutiva que configure el conocimiento de nuestra ciencia. De tal manera, difícilmente debe conferirse a la contabilidad mental ni siquiera la consideración de origen sino, estrictamente, de primeros atisbos de una mera inquietud de control innata en el hombre. A lo sumo, como una primera manifestación de la misma». Por lo que, la verdadera configuración científica de 
la Contabilidad encuentra sus primeras secuencias en el siglo XIX bajo la teoría personalista de Cerboni, pues aunque aportaciones anteriores tales como la obra de Pacciolo fueron de singular trascendencia, no fueron precisamente el hito de mayor consistencia para la calificación científica de nuestra disciplina. En último extremo, cabría situar el pasado histórico de la ciencia de la Contabilidad en las escuelas personalista y su precursora la lombardo-austriaca, o en todo caso, en la escuela contista de Degranges a finales del siglo XVIII.

Así, la configuración científica de la Contabilidad comienza con Fabio Besta, cuya doctrina parece merecer la calificación de origen de su pasado actual en el que podría situarse dicho origen. No obstante, dado el carácter paradigmático del principio de dualidad y el alto valor intrínseco de la recurrencia histórica de la obra de Pacciolo, podía situarse la ruptura que constituye el comienzo de nuestra ciencia en el año 1494, toda vez que con anterioridad, sólo se produjo un proceso de acumulación «característico predecesor de toda ruptura que, sucesivamente, va determinando en la que ésta se producirá.

Con posterioridad a Fray Lucas Pacciolo — según el profesor Requena— da comienzo un período de ciencia normal, y en el que aparece los característicos efectos de la ruptura. Por tanto, desde la enunciación de la partida doble en 1494, la Contabilidad rompe con su pasado, iniciando así, un proceso de desarrollo «en el que, sucesivamente, van tomando cuerpo diferentes concepciones, características de la ciencia normal, cuya presencia histórica se produce en los denominados período clásico y período científico» período actual (Requena, 1986).

El profesor Rivero Romero (1968) afirma que el «historiador de la ciencia constata con enorme frecuencia que los saberes prácticos, precientíficos, van constituyendo materiales acumulados sobre los cuales, en un momento determinado, la especulación del teórico asienta una nueva ciencia». Este párrafo, es aplicable en todo su contenido a la contabilidad, en tanto ésta ha ido fraguándose a través de un lento proceso de elaboración histórica. No es éste el contexto adecuado para ocuparnos rigurosamente del problema del devenir histórico de nuestra ciencia, pero si podemos realizar un somero análisis de su evolución a la luz de la teoría Kuhn.

Como afirma el profesor Túa Pereda (1983), la fuente dinámica para analizar e interpretar la evolución histórica de la Contabilidad es la perspectiva metodológica de Thomas S. Kuhn, lo que, según un sector de la doctrina, nos conduce a considerar que nos encontramos ante una revolución en nuestra disciplina; este pensamiento, al menos, expresa la profunda conmoción conceptual por la que atraviesa la Contabilidad. Más que una revolución, puntualiza dicho autor, es preferible pensar que la Contabilidad se enfrenta con una notable evolución de la base social en la que se asienta, que ha condicionado su cambiante papel tanto en la empresa como en el mundo que le rodea. En el mismo sentido, otros autores (Wells, 1976) han afirmado que la Contabilidad se encontraría emergiendo de un período de crisis, saliendo de una revolución de sus estructuras.

En nuestra disciplina, los hechos objeto de estudio de la Contabilidad no son permanentes ni repetibles como puede ocurrir en las ciencias naturales, éstos cambian constantemente y se modifican de acuerdo con las circunstancias del contexto que los rodean.

Pero, en cualquier caso, la idea de paradigma de Kuhn aplicada a nuestra disciplina, exige presuponer la existencia de una comunidad científica que comparta un conjunto de ideas que la mantenga unida. 
En relación con lo anterior, nos parece de importancia las precisiones que el profesor Requena (1986) realiza a propósito de sintetizar las concepciones epistemológicas de la ciencia contable, delimitando ciertos acontecimientos históricos de nuestra disciplina y poniendo de manifiesto algunos hechos re- levantes de su devenir histórico como cuerpo científico. En el siguiente cuadro obtenido del libro 100 ańos de Investigación Científica de la Contabilidad de Regulo Millán Puentes

Resumimos la evolución del pensamiento contable:

\begin{tabular}{|c|c|c|c|c|}
\hline ETAPAS & EDAD & $\begin{array}{l}\text { CONCEPTO } \\
\text { IMPERANTE }\end{array}$ & $\begin{array}{l}\text { INFORMACIÓN } \\
\text { REQUERIDA }\end{array}$ & $\begin{array}{c}\text { ELEMENTO } \\
\text { PREPONDERANTE }\end{array}$ \\
\hline $1^{\text {a }}$ & $\begin{array}{l}\text { En sus albores } \\
\text { primeros siglos }\end{array}$ & $\begin{array}{l}\text { Administración } \\
\text { Patrimonial }\end{array}$ & $\begin{array}{l}\text { ¿Qué tenemos y cómo } \\
\text { evitaremos que se pierdan? }\end{array}$ & $\begin{array}{l}\text { Teneduría de libros y } \\
\text { Balance Estático }\end{array}$ \\
\hline $2^{\mathrm{a}}$ & $\begin{array}{l}\text { En sus albores } \\
\text { siglos XII y XIII }\end{array}$ & $\begin{array}{l}\text { Rendición de } \\
\text { Cuentas }\end{array}$ & ¿Cuánto ganamos? & $\begin{array}{l}\text { Cuadro de Ganancias y } \\
\text { Pérdidas }\end{array}$ \\
\hline $3^{a}$ & $\begin{array}{l}\text { En sus albores } \\
\text { siglos XIV y XV. }\end{array}$ & $\begin{array}{l}\text { Intercambio y } \\
\text { crédito }\end{array}$ & $\begin{array}{l}\text { ¿Cuánto nos deben? } \\
\text { ¿Cuánto debemos? }\end{array}$ & Cuentas Corrientes \\
\hline $4^{a}$ & $\begin{array}{l}\text { Siglo XVI - XVII y } \\
\text { XVIII }\end{array}$ & $\begin{array}{l}\text { Prenda de garantía } \\
\text { Para terceras } \\
\text { personas }\end{array}$ & ¿Cuánto tenemos? & Activo y pasivo \\
\hline $5^{a}$ & Siglo XVII y XVIII & Negocio en marcha & ¿Cómo nos fue y cómo nos irá? & Balance dinámico \\
\hline $6^{a}$ & Siglo XVIII y XIX & $\begin{array}{l}\text { Expansión } \\
\text { Industrial }\end{array}$ & ¿Cuánto hicimos? & $\begin{array}{l}\text { Datos operativos, } \\
\text { Estados Financieros }\end{array}$ \\
\hline $7^{a}$ & Siglo XVIII y XIX & $\begin{array}{l}\text { Organización } \\
\text { Científica }\end{array}$ & ¿Cómo? & Sistemas y Métodos \\
\hline $8^{a}$ & Siglo XVIII y XIX & Productividad & ¿A qué costo? & Costos \\
\hline $9^{a}$ & Siglo XIX y XX & Rentabilidad & ¿Cuán buena es la inversión? & $\begin{array}{l}\text { Análisis de Estados } \\
\text { contables y económicos }\end{array}$ \\
\hline $10^{\mathrm{a}}$ & Siglo XIX y XX & Eficiencia & ¿Hacia donde vamos? & Auditoría \\
\hline $11^{\mathrm{a}}$ & Siglo XIX y XX & Planeamiento & ¿Cómo hacerlo mejor? & Presupuesto \\
\hline $12^{\mathrm{a}}$ & Siglo XIX y XX & Estrategia & ¿Cómo hacerlo mejor? & Investigación Operativa \\
\hline $13^{a}$ & Siglo XIX y XX & Sistematización & Información integral & Procesamiento de datos \\
\hline $14^{\mathrm{a}}$ & Siglo XIX y XX & $\begin{array}{l}\text { Políticas de } \\
\text { gestión }\end{array}$ & Desarrollo económico & Gerencia Eficiente \\
\hline $15^{\mathrm{a}}$ & Siglo XX y XXI & $\begin{array}{l}\text { Gestión del } \\
\text { conocimiento }\end{array}$ & $\begin{array}{l}\text { Cómo ser competitivos } \\
\text { Desarrollo social }\end{array}$ & $\begin{array}{l}\text { Gerencia Estratégica del } \\
\text { conocimiento. } \\
\text { Gerencia de Proyectos }\end{array}$ \\
\hline
\end{tabular}

\section{La tesis de Kuhn aplicada a la contabilidad}

La tesis de Kuhn no ha sido aplicada únicamente para estudiar el proceso de desarrollo científico de la Contabilidad, sino también para analizar la situación actual de la misma. En esta línea sobresalen los trabajos desarrollados por Wells y Belkaoui, y el documento Statement of Accounting Theory and Theory Aceptance (SOATATA) de la American Accounting Association (A.A.A.).
1.1. La matriz disciplinar en Contabilidad: Según Wells la Contabilidad evoluciona mediante un proceso continuo de sustitución de paradigmas. Apoyándose en el sentido amplio de paradigma como «matriz disciplinar», observando la conducta de los miembros de la comunidad científica. Esta comunidad científica comprende a los miembros de organizaciones de profesores e investigadores, tales como: la American Accounting Association, la Asociación de Profesores Universitarios de Contabilidad de Reino Unido, la Asociación de Contabilidad 
de Australia y Nueva Zelanda, la División de Investigación de la A.A.A. y la Fundación de Investigación Contable de Australia.

Esta opinión, es limitativa y restringida a la comunidad científica identificada a unos pocos países anglosajones y porque su propuesta no explica el proceso de crecimiento de nuestra ciencia, al descansar la matriz disciplinar o paradigma en un tipo de comunidad científica solamente identificable en el presente siglo. Esta comunidad científica no se adecua al sentido de universalidad con que Kuhn (1971) concibe la acción de paradigma.

Según Wells (1976), la matriz disciplinar de Kuhn estaría formada, por los siguientes elementos:

A. Generalizaciones simbólicas, que serían aquellos componentes generalmente aceptados y de fácil representación por el grupo:

- Partida doble.

- Clasificación de activo en fijo y circulante.

- Concepto de fondo de maniobra.

- Ratios contables.

- Apalancamiento financiero.

B. Acuerdos de grupo, que se corresponden con algunos de los considerados como principios de contabilidad generalmente aceptados:

- Principio de realización.

- Principio de asociación de ingresos y gastos.

- Principio de empresa en marcha.

- Principio del costo como base de valoración de activos.

C. Valores compartidos:

- Prudencia.

- Consistencia

- Importancia relativa.

D. Ejemplares, que se corresponderían con los manuales y documentos profesionales.
Wells analiza la mencionada matriz disciplinar con el fin de comprobar si en el momento presente nos encontramos ante un cambio revolucionario o de paradigma, para lo cual aplica el proceso metodológico desarrollado por Kuhn, señalando las siguientes fases:

a) Percepción de anomalias. Las principales anomalías detectadas por Wells se derivan de la incapacidad del sistema del costo histórico para representar la realidad económica de la empresa en épocas de globalización económica e inestabilidad monetaria.

b) Las crisis y emergencias de teorias. Un campo afectado por las anomalías puede calificarse como en estado de crisis profunda con lo que se exige la destrucción de paradigmas en gran escala y cambios importantes en los problemas y las técnicas de la ciencia normal. Por tanto, el surgimiento de nuevas teorías es precedido generalmente por un período de inseguridad profunda que es generado por el fracaso de la ciencia normal para dar las respuestas adecuadas. Aunque como subraya Kuhn se requiere que tras un período de debate el nuevo paradigma sea aceptado por la comunidad científica.

c) Creación de escuelas de pensamiento. Lo anterior da lugar a la aparición de dos grandes corrientes: una de defensa de la matriz que sustenta el principio del costo histórico (en su caso ajustado al nivel general de precios) y aquélla que pretende la utilización de un criterio de valoración a costo corriente. Wells identifica, de acuerdo con los diferentes criterios de valoración de activo, hasta cuatro escuelas diferentes que ofrecen respuestas alternativas al método de valoración del costo histórico:

1. La contabilidad ajustada al nivel general de precios. 
2. Contabilidad al costo de reposición.

3. Contabilidad en función del valor de la empresa.

4. Contabilidad al valor de realización neto o contabilidad continuamente actualizada.

La aceptación de un nuevo paradigma, de acuerdo con Kuhn (1971), exige la destrucción del paradigma anterior y el consiguiente conflicto entre escuelas del pensamiento científico opuestas, lo que dada la inconmensurabilidad de los paradigmas en competencia, se hace necesaria una transición entre paradigmas, donde los argumentos de persuasión para atraer a la comunidad científica como un todo son imprescindibles, hasta que el nuevo paradigma resulta dominante. Todo este proceso de transición constituye la revolución científica.

d) Habría que preguntarse si en la Contabilidad estamos asistiendo a una revolución que conduce a un cambio de matriz disciplinar; lo que, según Wells (1976), resulta prematuro verificar. Hoy, dados algunos cambios, principalmente de carácter normativo (legal o institucional), que se han producido en relación con la aceptación simultánea de ambos paradigmas (Mattessich, 1985), nos hace pensar que la labor de persuasión de la escuela que sustenta el nuevo paradigma o matriz disciplinar está dando frutos.

Esta tolerancia de paradigmas contrapuestos si seguimos a Kuhn, y contrariamente a la opinión de Mattessich que reconoce una matriz disciplinar por combinación de diferentes valores, sería un paso más en el cambio revolucionario y la mejor forma de consolidar, a través de la prueba, aquel paradigma cuya aceptación en la comunidad científica sea ma- yor, dado que las diferencias entre paradigmas son irreconciliables (Kuhn, 1971).

Asimismo, cabe cuestionarse si las tesis de Kuhn puedan ser aplicadas a una ciencia de las características de la Contabilidad, donde el entorno económico y social ejerce una influencia decisiva en su evolución, más que la investigación y el descubrimiento en las ciencias puras. En este sentido, hemos de destacar la opinión de Mattessich (1985) cuando señala que, más que un cambio paradigmático en Contabilidad nos enfrentamos con un cambio metodológico que puede conducir a una perspectiva, que posibilite y solvente cuestiones no planteadas.

\subsection{La concepción multiparadigmática de}

Belkaoui. Belkaoui (1985) somete a análisis la situación actual de nuestra ciencia tomando como referencia los diferentes enfoques de la misma contenidos en el informe «Statement of Accounting Theory and Theory Aceptance» (SOATATA) de la American Accounting Association (AAA), sobre la base de la noción de paradigma kuhniano, que según el es una imagen esencial de la materia subjetiva de una ciencia, que sirve para definir lo que debiera ser utilizado, las preguntas que hay que hacerse y las reglas que deben seguirse para interpretar las respuestas obtenidas. En definitiva, se trata de la unidad mayor de consenso en una ciencia y sirve para diferenciar una comunidad científica de otra. Belkaoui señala la existencia de una multiplicidad de paradigmas, que se encuentran en pugna por lograr la máxima aceptación en la comunidad contable:

a) Paradigma antropológico-inductivo ${ }^{8}$. Se basa en la inferencia de teorías a partir de la observación empírica. Según el

8 Destacan en él autores como: Haldfield (1927), Gilman (1939), Littleton (1953), Paton y Littleton (1940) e Ijiri (1975) en Donoso Anés (1995). 
profesor Túa (1991a), sus principales características son:

- Explica y justifica las prácticas más comunes o habituales, compilándolas, $\mathrm{y}$ comparándolas para inducir desde ellas los principios o fundamentos básicos en los que se sustentan.

- Las prácticas existentes en un momento determinado, se sustentan en la racionalidad del mundo de los negocios.

- Se limitan a exponer sintéticamente las prácticas habituales y a justificarlas por referencia a aquella experiencia y racionalidad mercantil.

\section{b) Paradigma del beneficio verdadero-} deductivo9. Se caracteriza por la elaboración de la teoría contable a partir de enunciados apriorísticos, pudiendo señalarse como rasgos característicos de este enfoque los siguientes:

- Búsqueda de la mejor práctica contable posible (carácter normativo) apoyada en conceptos fundamentalmente económicos -valor, renta y riqueza-, desarrollándose teorías con un contenido muy acentuado en los problemas de valoración, apartándose, frecuentemente, de los criterios del costo histórico.

- Búsqueda de una concepción ideal del beneficio a través del cual poder comprender todo el proceso contable.

- Utilizan el método deductivo; es decir, partiendo de una serie de postulados, axiomas y premisas, deducen las reglas contables que deben seguir las empresas (Pina, 1991b).
A tales características, cabe añadir, como señala el profesor Túa (1991b), «la utilización del concepto de verdad, por encima del de utilidad, con lo que se produce la búsqueda de una verdad contable única, es decir, de la mejor medición y representación posible de la situación patrimonial y del beneficio, independientemente de quien recibe la información, sin apenas considerar, por tanto, la posible incidencia en los sistemas contables de un conjunto dispar de objetivos, originados por la existencia de diferentes tipos de usuarios».

c) Paradigma de utilidad de la decisiónmodelo de decisión ${ }^{10}$. Establece que la utilidad de la información contable está en función de su capacidad para ofrecer los datos relevantes para el usuario de la misma, siendo la información más relevante aquella que potencialmente pueda proporcionar más datos en relación con las necesidades de los modelos de decisión empleados por el usuario. Con respecto a los demás paradigmas de utilidad, cabe señalar como otra característica distintiva el que los investigadores que lo siguen trabajan, principalmente, con modelos normativos (Wolk, Francis y Tearney, 1984). Según Belkaoui (1985), la utilidad de la información se determina por su capacidad predictiva ya que no es posible tomar decisiones sin una predicción.

\section{d) Paradigma de utilidad en la decisión- decisor-comportamiento agrupado del mercado $^{11}$. Los investigadores, según este}

9 Los autores más significativos son Paton (1922), Canning (1929), Sweency (1936), MacNeal (1939), Alexander (1950), Edwards y Bell (1961), Moonitz (1961), Sprouse y Moonitz (1962), en Donoso Anés (1995).

10 Destacan Beaver, Kevedy y Ross (1968), y Sterling (1972), en Donoso Anés (1995).

11 Los autores más representativos son Gonedes (1972), Gonedes y dopuch (1974) y Beaver (1972), en Donoso Anés (1995). 
paradigma, orientan sus trabajos a valorar la incidencia de las cifras contables en las decisiones de los usuarios. De esta forma, tomando como indicador de tal incidencia las cotizaciones bursátiles, se preocupan por analizar la relación entre la información contable y los precios de las acciones, intentando identificar la incidencia que tal información tiene en los referidos precios. Así, se pretende estudiar la utilidad de la información para los usuarios considerados como grupo. El profesor Túa (1991a) afirma que «la asunción básica del enfoque de mercado es la hipótesis de eficiencia que presupone aquella situación en la que los precios de cualquier acción constituyen una buena estimación de su valor intrínseco, a la vez que cuando se suministra una nueva información al mercado, útil para la evaluación del riesgo y de las tasas de retorno esperadas de las acciones, se alcanza un nuevo equilibrio, en el que los precios incorporan aquella información, reaccionando ante la misma de forma rápida y no sesgada».

\section{e) Paradigma de utilidad en la decisión-} decisor-usuario individual ${ }^{12}$. Trata de analizar la relación existente entre la información contable suministrada y el impacto que esta produce en la conducta o comportamiento de los usuarios, individualmente considerados (Túa, 1991a). Para Belkaoui (1985), en este enfoque se asume que el propósito de la Contabilidad es influir en la conducta del usuario a través de la información del mensaje que se comunica. Por su parte, el profesor Túa (1991a) distingue dos vertientes distintas dentro de este enfoque, la teoría del comportamiento y la teoría de la información:

- La teoría del comportamiento se basa en que el propósito principal de la información financiera es influenciar la conducta de los usuarios, lo cual está en función del comportamiento de los que elaboran y reciben dicha información y de sus reacciones ante la misma.

- La teoría de la información tiene como finalidad básica evaluar la manera en que se emiten, reciben y procesan los estados financieros.

\section{f) Paradigma del valor económico de la} información ${ }^{13}$. Concibe la información contable como un bien económico cuya producción genera un costo y reporta un beneficio, por lo que las decisiones en torno a tal producción de información deben ser evaluadas en un marco de costo-beneficio (Kieso y Weygandt, 1984). Esto es, la producción de información se rige por las leyes de oferta y demanda, evaluándose su utilidad en función de su capacidad para mejorar las decisiones del individuo, quien selecciona la mejor de las alternativas posibles. El sistema óptimo será aquel que presente mayor diferencia entre el beneficio producido por la información y el coste de generación de la misma (Túa, 1991a). En opinión del profesor Túa (1991a), el único paradigma que puede considerarse en el sentido de Kuhn es el de utilidad, siendo los demás desarrollos o enfoques del mismo, posición que, asimismo, mantiene la profesora Giner Inchausti (1994), para quien la

12 Destacan Bruns (1968), Holsfedt y Kinard (1970), así como Birnberg y Nath (1967), en Donoso Anés (1995).

13 En él destacan autores como Feltham (1968 y 1972), Grandall (1969), Demski y Feltham (1969 y 1976), en Donoso Anés (1995). 
actual etapa de la Contabilidad se caracteriza por la presencia de un único paradigma alternativo, el de utilidad, que presenta distintos enfoques que no se contradicen.

\section{Los programas de investigación lakatosianos aplicados a la contabilidad}

El análisis de la evolución científica de la Contabilidad nos ha venido enseñando que sus planteamientos se transforman a lo largo del tiempo, y que se enfrentan a cambios más o menos profundos, confirmando que estamos ante una realidad dinámica en la que el último destino de las teorías vigentes en cada momento es el de ser sustituidas por otras más eficientes. En este contexto, la metodología de los programas de investigación ofrece una nueva reconstrucción racional de la ciencia, bajo cuya concepción, las más grandes realizaciones científicas constituyen programas de investigación que son susceptibles de ser evaluados en términos de cambios progresivos y degenerativos. En este sentido, creemos oportuno poner de manifiesto que todo programa de investigación constituye un conjunto de reglas heurísticas positivas que tienen la misión de indicar las líneas de investigación que deben seguirse y un conjunto de reglas heurísticas negativas que nos muestran los caminos que se deben evitar.

La aplicación de los planteamientos de Lákatos a la ciencia moderna ha sido desarrollada, principalmente, por los profesores Cañibano Calvo (1974, 1979, 1996) y Montesinos Julve (1978). El profesor Cañibano entiende que los diferentes programas de investigación, en cuyo marco se han desarrollado las elaboraciones contables, son tres, y que atendiendo al elemento que ha servido de base para su configuración, denomina: legalista, económico y formalizado. a) El programa legalista. Se remonta a los orígenes de la partida doble y surge de «la utilización de la información contable para mostrar el patrimonio del comerciante como prueba de su garantía respecto al cumplimiento de sus obligaciones actuales y futuras» (Cañibano, 1979). La finalidad de nuestra disciplina entra en una línea especialmente jurídica, según la cual el objetivo de la información es de carácter eminentemente legalista.

b) El programa de investigación económica. Nace con Eugen Schmalenbach, después de la inflación desatada tras la Primera Guerra Mundial, sobre todo en Alemania, al convertirse en obsoletas las informaciones histórico-contables del enfoque legalista, al no cumplir estas con la función evaluadora del patrimonio como garantía frente a terceros. Podría decirse que nos encontramos "con unas circunstancias que alteran totalmente el papel de la información contable, se le pide que sea capaz de ofrecer una base de cifras realistas, que se adapte al medio, que los resultados calculados respondan a principios económicos, que su conocimiento verdadero evite la creciente descapitalización de las empresas» (Cañibano, 1974). De esta forma, sin abandonarse el aspecto estrictamente legal, los objetivos de la información contable quedaban ya más orientados hacia los aspectos puramente económicos de la actividad empresarial. Eugen Schmalenbach, en su obra El Balance Dinámico, realiza los siguientes aportes del mencionado programa:

- Progreso importante en el campo de la normalización contable.

- Extraordinario desarrollo de la Contabilidad de Costos. 
- La cuenta de Ganancias y Pérdidas comienza a configurarse como el estado contable base frente al balance General (Cañibano y Bueno, 1983) (Casanovas, 1976) (Rivero Torre, 1972).

El programa económico ha cristalizado en tres subprogramas diferentes que acentúan la relación entre la Economía y la Contabilidad:

- El beneficio verdadero. Es de tipo deductivo-normativo, con el objetivo de determinar reglas de valoración para derivar aquellas medidas contables (beneficio a costo histórico, ajustado por inflación, a costo corriente, flujo de tesorería de las operaciones, etc.) que pueden servir para los usuarios, sea cual sea su interés e implicación en la empresa.

- Utilidad para el decidor. Sus seguidores «toman para sí la tarea de elaborar, en función de las características de cada entorno de decisión, el modelo que puede maximizar el provecho obtenido por el sujeto, ya sea construyendo reglas técnicas de decisión a través de modelos de corte normativo, ya teniendo en cuenta la conducta del sujeto o las características propias del procesamiento humano de la información».

- Teoría contable positiva. Podríamos afirmar junto a los mencionados autores, que se intenta construir "una teoría que trate de explicar las normas y la práctica contable existente, incluyendo la identificación de los factores e intereses económicos que contribuyen a determinarlas».

c) El programa de investigación formalizado. Aparece cuando se produce la aplicación de la rigurosidad formal de las matemáticas a la metodología contable, a partir de la Segunda Guerra Mundial, concretamente a finales de la década de los cincuenta. Precisamente, en 1964, Richard Mattessich, en su artículo «Accounting and Analytical Methods», culmina la mencionada formalización en el marco de la teoría de conjuntos y apoyándose en el álgebra matricial como lenguaje formal.

A juicio del profesor Cañibano (1974), nos encontramos con que la nota más característica del programa de investigación de la ciencia contable es su formalización, es decir, «el reducir sus proposiciones a cálculos lógicos o matemáticos, para en virtud de las reglas interferenciales, llegar a unos resultados capaces de ser interpretados semánticamente, y cuyo contraste con la realidad irá elevando de día en día su potencialidad explicativa y predictiva». Recientemente, los profesores Cañibano Calvo y Gonzalo Angulo (1995) han profundizado en esta clasificación de programas, actualizando sus contenidos y tendencias.

Para ellos, los viejos programas (legalista, económico y formalizado) pueden resistir la evolución metodológica partiendo de las ideas de Kuhn y Lákatos -redes de teorías de Stegmüler y familias de áreas de investigación de Bunge- dada la «flexibilidad con que fueron planteados, por el pluralismo teórico o metodológico que llevaban consigo, porque claramente representaban tradiciones de investigación que competían entre sí más que teorías excluyentes».

En cuanto al programa formalizado, se concibe, ahora, integrado por un conjunto de subprogramas:

- Axiomatización de la Contabilidad (Paton, Devine, Litleton, Chambers, Matessich).

- La teoría de la agencia (Jensen y Meckling). 
- Modelos de información económica (Feltham, Chandall).

- El análisis circulatorio.

- Modelo de precios de activos financieros -CAMP-/hipótesis de eficiencia de mercado -HEM- (Watts y Zimmerman). Según el profesor Montesinos Julve (1978), el programa matemático o formal en tanto incluya la Contabilidad dentro de las teorías matemáticas, debe ser rechazado. Pero, continúa diciendo el citado profesor, "cuestión diferente es la utilización de lenguajes científicos rigurosos y formalizados, como el de la matemática, en la expresión de las teorías contables». Así, «una de las características de los actuales programas de investigación en Contabilidad es el empeño formalizador.

Entonces podemos concluir que la contabilidad no es ajena a las posturas epistemológicas y filosóficas; más bien, esta se alimenta de ellas. De estas posturas epistemológicas se derivan las siguientes teorías contables:

\begin{tabular}{|c|c|c|}
\hline & PRECURSORES & FUNDAMENTO \\
\hline TEORÍA JURÍDICA & $\begin{array}{l}\text { ESCUELA PERSONALISTA } \\
\text { DE LA CONTABILIDAD } \\
\text { GUISEPPE CARBONI }\end{array}$ & $\begin{array}{l}\text { LA CONTABILIDAD TIENE POR OBJETO ESTABLECER LA } \\
\text { RESPONSABILIDADES JURÍDICAS SURGUIDAS COMO CONSECUENCIA } \\
\text { DE UNA GESTIÓN O ADMINISTRACIÓN PATRIMONIAL. POR ESTA TEORIA } \\
\text { LOS ASIENTOS CONTABLES CREAN DERECHOS Y OBLIGACIONES. }\end{array}$ \\
\hline TEORÍA ECONÓMICA & $\begin{array}{l}\text { ESCUELA ECONÓMICA } \\
\text { FABIO BESTA } \\
\text { TEORÍA CONTROLISTA } \\
\text { TEORÍA DEL VALOR }\end{array}$ & $\begin{array}{l}\text { EL CONTROL ECONÓMICO QUE REALIZA LA CONTABILIDAD LO HACE } \\
\text { EN SU TRIPLE FUNCIÓN: CONTROL ASCENDENTE, CONCOMINANTE, Y } \\
\text { CONSECUENTE. POR ESTA TEORÍA LAS ANOTACIONES EN EL DEBE } \\
\text { SON ENTRADAS Y LAS DEL HABER SON SALIDAS. }\end{array}$ \\
\hline $\begin{array}{l}\text { TEORÍA } \\
\text { ADMINISTRATIVA }\end{array}$ & $\begin{array}{l}\text { HENRY FAYOL } \\
\text { INCLUYE A LA } \\
\text { CONTABILIDAD ENTRE } \\
\text { LAS FUNCIONES BÁSICAS } \\
\text { DE TODA ORGANIZACIÓN } \\
\text { EMPRESARIAL }\end{array}$ & $\begin{array}{l}\text { LA ORGANIZACIÓN CONTABLE DEBE ADAPTARSE A LA ORGANIZACIÓN } \\
\text { ADMINISTRATIVADELAENTIDAD. ENLA APLICACIÓNDELOSPRINCIPIOS } \\
\text { Y LEYES CONTABLES NO PUEDE HABER ACTO ADMINISTRATIVO SINO } \\
\text { ES CONSECUENCIA DE UN MOVIMIENTO CONTABLE; NI OPERACIÓN, } \\
\text { CONTABLE SIN SU CORRESPONDIENTE ACTO ADMINISTRATIVO. }\end{array}$ \\
\hline $\begin{array}{l}\text { TEORÍA MATEMÁTICO- } \\
\text { CONTABLE }\end{array}$ & $\begin{array}{l}\text { GUISEPPE FORNI } \\
\text { A. MAITRE } \\
\text { GIOVANNI ROSSI } \\
\text { RICHARD MATTESSICH }\end{array}$ & $\begin{array}{l}\text { PARA ROSSI, TODAS LAS MODIFICACIONES QUE EXPERIMENTA } \\
\text { EL PATRIMONIO DE UNA EMPRESA COMO CONSECUENCIA DE LAS } \\
\text { OPERACIONES QUE REALIZA, PUEDEN ESTAR REPRESENTADAS POR } \\
\text { ECUACIONES: A-P=PN. } \\
\text { MATTESSICH: AXIOMATIZACIÓN DE LA CIENCIA CONTABLE. }\end{array}$ \\
\hline $\begin{array}{l}\text { TEORÍA DE LA } \\
\text { EFICACIA Y EL VALOR } \\
\text { DE LA EMPRESA* }\end{array}$ & $\begin{array}{l}\text { PROVEEDOR DE IDEAS } \\
\text { FUNDAMENTALES PARA } \\
\text { CONSOLIDAR UNA } \\
\text { ECONOMÍA COMPETITIVA } \\
\text { DE LA EMPRESA. }\end{array}$ & $\begin{array}{l}\text { ENFOQUE SISTÉMICO INTEGRADO (INCLUYE LAS TEORÍAS DE LAS } \\
\text { CIENCIAS SOCIALES EN ESPECIAL LAS EMPRERSARIALES QUE } \\
\text { CONVERGEN CON LA CONTABILIDAD) } \\
\text { USO DE HERRAMIENTAS MODERNAS COMO: BALANCED SCORECARD, } \\
\text { PROJECT (GESTIÓN DE PROYECTOS). }\end{array}$ \\
\hline
\end{tabular}

* Esta teoría propuesta por nuestra investigación debe ser materia de estudio para el futuro.

\section{MARCO TEÓRICO DE LA CONTABILIDAD DEL CONOCIMIENTO}

\section{El enfoque sistémico integrado de la contabilidad del conocimiento}

Tanto el hombre común como el filósofo o el científico entienden, a su manera, la con- cepción del mundo. A menudo se animan ciertas posturas filosóficas e ideológicas, como por ejemplo, creer en un ser extraordinario que creó todas las cosas (religión), o la explicación científica de que el universo, y, por ende, la vida, se originó en el Big Bang (materialista).

En general, existe un hombre común que percibe la realidad diferente a la per- 
cepción del científico; entonces, haciendo la misma analogía, podríamos decir que existe un profesional contable común y un profesional contable científico. Ambos tendrán concepciones diferentes y distantes de la contabilidad. El profesional común tiene la concepción practicista operativa de contabilidad (atomista), el científico tiene un enfoque sistémico integrado y holístico de la estructura donde va cambiando la contabilidad, ya que esta se encuentra inmersa en un contexto mudable.

El contador que aplique el enfoque sistémico integrado evita las visiones unilaterales o sectoriales, y las correspondientes soluciones simplistas de la profesión. El enfoque sistémico integrado admite la necesidad de estudiar los componentes de un sistema en la totalidad de su contexto pero no se limita a ellos. Por ello, me atrevo a decir que para el proceso de metateorización de la contabilidad del conocimiento es ineludible encontrar el esperanto de este enfoque sistémico y contextual. Asimismo, existe la posibilidad de que en el proceso de formalización de este conocimiento contable se presenta ciertos aspectos cognitivos y no cognitivos, no por ello, implica la inadecuada axiomatización del asunto, por el contrario sería el camino correcto para llegar a construir tal teoría.

En simples palabras, debemos defender el enfoque sistémico integrado, que nos conduce al contextualismo epistemológico, puesto que sería el vector que empuje a la comunidad contable (científicos) a no dejar de lado los demás sistemas de referencia del contexto.

En conclusión, este enfoque sistémico integrado y contextualista de la ciencia contable es un sistema global y estructurado que se mueve con la historia y avanza por medio de la superación de contradicciones. Dar validez a los factores pragmáticos es de suma importancia puesto que estos constituyen los elementos que integran el contexto. En realidad, «una teoría pura del conocimiento que no tenga en cuenta el resultado de las ciencias empíricas operaria en el vacío o degeneraría en un apriorismo dogmático», esto es como la filosofía elemental de Kant, quien decía: «los pensamientos sin contenidos son vacíos, las instituciones sin conceptos son ciegas»; por lo tanto, la teoría contable sin ningún enfoque sistémico contextual sería como una hoja en blanco esperando que alguien escriba en ella.

Aunque debemos precisar, el enfoque sistémico es necesario pero no suficiente. Para una auténtica síntesis paradigmática ${ }^{14}$ requerimos nuevos marcos teóricos conceptuales y nuevos marcos normativos (y no excluyen las existentes, sino las complementa, las perfecciona). Tenemos una gran tarea por adelante: la reforma sustantiva de la profesión acorde a la era de la información y del conocimiento

\section{Determinación del contexto contable para teorizar la contabilidad del conocimiento}

Los investigadores contables que han realizado "Teoría Contable» trabajan cada uno a su manera y en forma aislada según su inclinación ideológica e influencia escolástica, sumando así muchos conceptos a la enmarañada literatura contable existente. Bajo esa modalidad investigativa, se ha llegado inclusive a confundir al propio investigador; por lo que, para no producir más vacíos y añadir conceptos en esa pluralidad contable,

14 La síntesis paradigmática es una realidad epistemológica gracias a la emergencia de ciencias puramente interdisciplinarias y multidimensionales como son las ciencias socionaturales y las sociotecnologías. 
en la presente investigación, determinamos el contexto en la cual debemos desarrollarla considerando para ello el Enfoque Sistémico Integrado.

El citado enfoque nos da una visión de la realidad contextual donde se desarrolla la contabilidad que no puede ser separada de aspectos tales como: económico, político, cultural, psicológico, ecológico, y hasta biológico. Es decir, es en ese contexto sistémico integrado que interpretaremos el pensamiento de la contabilidad del conocimiento, como parte de un sistema conceptual y no como un fragmento de la ciencia económica. Sin embargo, no debemos obviar «El Contexto Sistémico de la Contabilidad» o contexto tetradimensional que con sus compartimentos interactuantes impulsan el desarrollo de la metateoría de la contabilidad del conocimiento. Estos compartimentos son:

(i) El aspecto social, el cual abarcó muchos grupos sociales pues la contabilidad está inmersa en ella, es un impulsor no cognoscitivo.

(ii) El aspecto histórico, ya que la investigación científica se da a lo largo de la historia generando nuevas tradiciones paradigmáticas.

(iii) El aspecto empírico, el cual es de naturaleza cognoscitiva.

(iv) Lo conceptual, cuya naturaleza es cognoscitiva.

\section{Fundamentos para la metateorización de la contabilidad del conocimiento}

Bajo el Enfoque Sistémico Integrado de nuestro estudio y habiendo definido los fundamentos por medio de los cuales debemos empezar la metateorización de la contabilidad del conocimiento, llegamos a la conclusión que el conocimiento contable no puede ser estático, sino dinámico; es decir, trans- portable en el espacio y tiempo, y adaptable a la realidad del contexto, ya que la ciencia y la técnica deben avanzar con ella.

Analicemos sobre la naturaleza del Capital, que es un concepto que hasta la fecha no deja de transformarse y que ha sido de materia de análisis por muchos investigadores clásicos, los cuales han llegado a la conclusión que «el capital es por naturaleza siempre inmaterial, puesto que no es la materia lo que hace al capital sino el valor de aquella materia; el valor no tiene nada de físico». Carlos Marx, decía «Tenemos que ir más allá de la Física para tocar a la gallina que pone los huevos de oro». Entonces, por qué la comunidad contable sigue pensando que el capital es de naturaleza estática y no dinámica, me parece que es una cuestión de enfoque cognoscitivo y de contexto. Por lo tanto, «si el cambio al capital-conocimiento es real, significa que el capital en sí es cada vez más irreal, que se compone en su mayor parte de símbolos que representan nada más que otros símbolos... ", es en esta donde la contabilidad debe matematizar el capitalconocimiento para su real comprensión.

De lo anterior podemos concluir que nos enfrentamos a un nuevo capital que no está compuesto solo por inversiones tangibles, sino, también, por un capital basado en la capacidad de las personas denominado capital intelectual. Pero, ¿qué hace que este capital relacionado con los recursos humanos sea más competitiva? En el ambiente actual que rodean a los negocios, aparecen los impulsores inmateriales conocidos como fuerzas endógenos y exógenos, los cuales serán determinantes para la valorización del capital de acuerdo con su performance. Este análisis realizado guía el desarrollo de nuestro pensamiento contable y la rigurosidad que podamos imprimirle será determinante para llegar a su metateorización, que contenga una: 
(i) metodología,

(ii) instrumentos y técnicas,

(iii) una matriz básica,

(iv) un cinturón centinela

\section{Teoría de la convergencia contable}

Para alcanzar una teoría unificada de la contabilidad del conocimiento, debemos, primero, metateorizar, vale decir que de la teoría contable existente debemos llegar a una teoría más general. Es decir, partiendo de los estadios primitivos del pensamiento contable, debemos llegar a los estadios de la sistematización para alcanzar el status de cientificidad. Con esta afirmación, defendemos la evolución del objeto contable realizadas por las diversas escuelas, pero sentamos las bases para una revisión dialéctica de los estadios pre-teoréticos.

Para esta revisión dialéctica, consideraremos la crisis actual que afecta a la contabilidad y el Enfoque Sistémico Integrado. A lo largo de la historia de la humanidad, han existido ciencias en crisis que, para no llegar a la extinción, se han solapado con otras vecinas ya que no hay ciencia aislada, bajo el enfoque sistémico. Es por ello que aparecieron, por ejemplo, la biofísica, bioquímica, fisiología, geoquímica, etc.

Entonces, por analogía, bajo esta realidad, debemos aplicar la Teoría de la Convergencia $^{15}$, es decir, sí a esta teoría añadimos el enfoque sistémico integrado de la contabilidad, esta debe analizarse en el campo de las ciencias sociales y específicamente en las ciencias económico-empresariales. Por lo que, debemos, analizar nuestra teoría en el contexto de la economía, administración, psicología, ecología, etc.

\section{Analisis crítico del método contable tradicional, para concebir la contabilidad del conocimiento}

Comencemos este análisis crítico entendiendo que el término método queda referido al estudio del desarrollo, validación, y si procede, la refutación de una teoría científica, aun cuando entendido de forma clásica, serían aquellos procedimientos utilizados hacia la búsqueda de una verdad.

En la Ciencia Contable, el método contable vigente lleva a cabo una serie de funciones específicas que podrían enmarcarse en el denominado método operativo que realiza para la consecución de sus objetivos. El profesor Cañibano (1996) define al método contable, como "un conjunto de postulados $y$ premisas subsidiarias que permite someter a observación la realidad económica, expresar en un lenguaje convenido los aspectos cualitativos y cuantitativos de dicha observación conforme a unas reglas que garantizan un determinado grado de objetividad, y procesar la información resultante siguiendo unos criterios que permitan obtener estados sintéticos que contengan agregados relevantes".

Esta metodología específica que actualmente desarrolla la contabilidad para obtener y suministrar información del ente y la evolución de determinadas realidades económicas, se materializa con las funciones de captación, simbolización, medida, valoración, representación, coordinación, agregación, que junto a las de análisis e interpretación; que nacen inicialmente de un proceso de inducción que posteriormente se torna en un proceso deductivo, que permite la obtención de la realidad económica revelada, y representativa, en términos contables, de una rea-

15 Darwin Malpartida, en el XIX Congreso de Contadores Públicos del Perú, dijo que «una teoría convergente es un conjunto de modelos teoréticos de otras ciencias que se pueden aplicar sin ninguna contradicción y ambigüedad a la contabilidad». 
lidad que mediante una simple observación se presentaría inexpresiva y desordenada. Entonces, según el profesor Calafell (1971), el Proceso Metodológico Contable Integral está integrado por:

Razonamiento inductivo. El mismo que culmina con la obtención del Balance, y dentro de aquel se distinguen dos partes fundamentales:

- Una de naturaleza cientifica, en la que se lleva a cabo la captación, simbolización, medida y valoración de la realidad económica.

- Otra de naturaleza técnico-formal, que se ocupa de la representación, coordinación e integración de dicha realidad hasta llegar a la formulación del Balance de situación.

Para fundamentar teóricamente la contabilidad del conocimiento, el proceso científico del razonamiento inductivo debe modificarse, ya que en la actualidad, la realidad económica de los negocios nos indican que son los hechos y/o asuntos cualitativos los que generan valor a las organizaciones empresariales. Esta primera afirmación detectada nace del enfoque sistémico integral que debe realizar el profesional contable a fin de analizar y actualizar detalladamente su accionar en el proceso de captación, simbolización, medida y valorización a fin de emitir información válida en el ámbito de la nueva economía.

Razonamiento deductivo. El cual tiene lugar a partir del Balance y se caracteriza porque permitirá revelar la realidad económica del ente en todos sus aspectos, constituyendo así el proceso de análisis contable. A su vez, en este subproceso se distinguen dos aspectos fundamentales:

- Análisis de la historia económica. Se desprende de la Contabilidad, e implícitamente del Balance y documentos anexos.

- Análisis prospectivo o de expectativas. Sirve de base en la toma de decisiones futuras sobre la gestión a realizar.
El razonamiento deductivo actual que realiza el profesional contable parte de un balance con limitaciones de información, ya que solo reportamos hechos económicos históricos medidos cuantitativamente, sin considerar los hechos y asuntos cualitativos que actualmente en la nueva economía son de vital importancia para realizar el análisis prospectivo que sea útil en la toma de decisiones de la gestión de negocios.

En conclusión, si bien es cierto que tanto el razonamiento inductivo y deductivo son los pilares de la metodología contable, estos deben ser actualizados y/o modificados de acuerdo con los nuevos paradigmas contables en la nueva economía.

Subproceso intermedio. El que se ocupa de dos importantes problemáticas contables:

- La verificación o constatación contable en su doble aspecto técnico- contable y económico.

- La consolidación o integración contable de varias situaciones económicas en una sola situación.

El subproceso de verificación o constatación debe ser aplicado con herramientas y técnicas modernas de identificación de hechos económico-financieros y hechos cualitativos que son las variables a ser captados, medidos y valorizados por la contabilidad en el marco de la nueva economía.

\section{A. La captación contable}

El programa de investigación en que se desenvuelve actualmente nuestra disciplina, eminentemente formal, asigna a la misma la función de captación, o como afirma el profesor Calafell, «captar, considerando a la realidad desde un plano de observación, y por tanto, los estímulos que en dicho plano se perciben, los somete a cómputo 
y representación contable». Nuestra disciplina pretende, pues, el conocimiento de una realidad normalmente económica que necesitará, previo a cualquier otro proceso, captar la fenomenología inherente a la misma, para que, con posterioridad proceder a su representación.

Al haberse modificado esta realidad en el marco de la nueva economía, han aparecido, como consecuencia de ella, nuevos paradigmas contables, que deben ser analizados por el enfoque sistémico integrado en el proceso de la metateorización de la contabilidad del conocimiento con la finalidad de cumplir con los objetivos de informar sobre aspectos cuantitativos y cualitativos que se requieren.

El enfoque sistémico integrado nos induce a modificar el Plano de Observación de los hechos a ser contabilizados; esta se debe situar en el nivel estratégico de las organizaciones, con la finalidad de tener una visión conjunta del contexto en la cual se desenvuelve la organización, ya que solo a este nivel estaremos captando datos de una realidad no vista por la contabilidad tradicional.

Esta modificación del Plano de Observación de los hechos contables necesita de un sujeto contable cognoscente que requiere conocer la realidad del contexto -objeto material y capital intelectual- cuya imagen se pretende transmitir para poder contabilizarlo. Es decir, en este nivel se debe captar los intangibles generadores de beneficios y de valor para las organizaciones.

El sujeto contable cognoscente debe estar preparado para captar esta nueva realidad de la contabilidad con la finalidad de que su capacidad y limitaciones, sean las determinantes en la identificación, registro y valorización de los hechos contables que actualmente están basados por un claro subjetivismo en los juicios de valor desde el estadio inicial del método operativo contable.

Por su parte, esta nueva representación de los hechos contables debe entenderse en un sentido multidimensional y no solo dual como lo es actualmente, ya que de ella dependerá la medición y valoración del hecho contable del mundo real. Sin embargo, el problema de medición es estrictamente un problema de representación que surge después de que las relaciones entre los objetos están completamente comprendidas.

\section{B. La medición contable}

La Contabilidad desarrolla la función de medición, una vez captados la totalidad de elementos que configuran la realidad. Nuestra doctrina asume la vinculación expresa de la Contabilidad con la teoría de la medición; sirvan a tal efecto la tesis del Comité encargado por la American Accounting Association ${ }^{16}$ para el estudio de los fundamentos de las Mediciones Contables es la siguiente: «La medición contable consiste en la cuantificación de los fenómenos económicos pasados, presentes o futuros de la entidad, bajo las bases de observación y conforme unas reglas» (Ijiri; Mattessich y otros, 1971; 3).

Entonces, la medición contable implica un proceso de abstracción de algún aspecto de los sucesos, fenómenos o realidades a medir, que deben ser adaptadas considerado que la captación contable, debe identificar las fuentes de conocimientos y los datos de los sucesos inmateriales confortantes del capital intelectual; que obliga al sujeto contable cognoscente a replantear el

16 Ijiri,Y., 1967. Sin embargo, ésta opinión no debería ser tan tajante cuando no ha sido ésta la tesis del Comité de la AAA sobre la medición presidido por el propio Ijiri. 
proceso de medición contable tradicional, incluyendo en ella, la necesidad de obtener datos cuantitativos del nivel estratégico de la organización relacionados con las fuentes de conocimientos que generan valor (aspectos cualitativos que están cuantificados como indicadores), las cuales al aplicarse en la gestión de negocios como información precisa y objetiva, inciden en la rigurosidad del método científico de la contabilidad.
El proceso de medición actual está integrado, como lo planteo el profesor Ijiri (1967), por tres factores principales:

- Un objeto cuya propiedad va a ser medida.

- Un sistema de medición integrado por un conjunto de reglas e instrumentos.

- Una persona que realiza la medición.

Lo anterior lo sistematiza como exponemos a continuación:

\section{FACTORES DEL PROCESO DE MEDICIÓN}

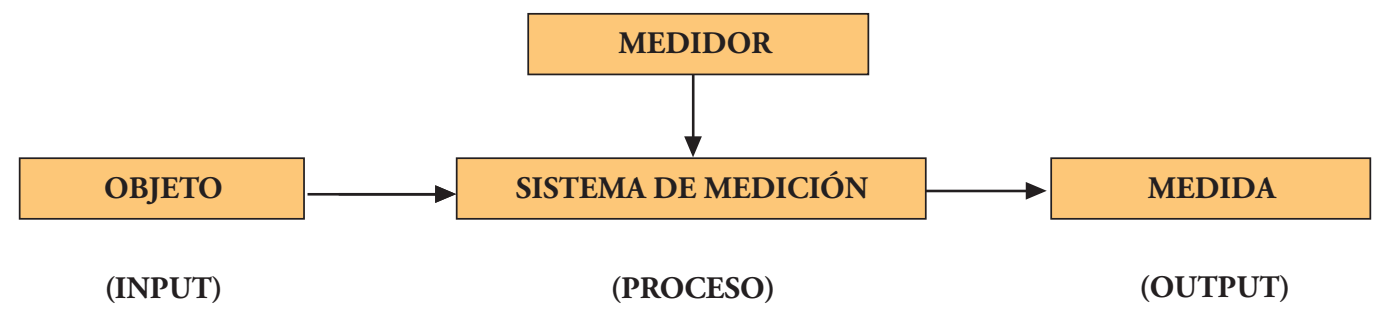

Este proceso de medición debe ser modificado para la contabilidad del conocimiento,

- El imput de la valorización debe incluir el factor de información (indicadores) que se conciben en el nivel estratégico de la organización.

- El sistema de medición debe realizar el proceso de valorización financiera, considerando los datos provenientes de la gestión de los activos intangibles. Esto es factible ya que las estrategias se convierten en datos financieros; y estos, a su vez, en indicadores que pueden ser comparados con los estimados inicialmente.

- La valorización del capital intelectual se realizaría comparando individualmente el cumplimiento de los objetivos y metas estratégicos establecidos, que son los determinantes en la valorización de la empresa. Stevens define cuatro tipos de escalas basando su discriminación en función a la estructura matemática de los grupos de transformación que las definan. Estas escalas son:
- La escala nominal o de clasificación. La cual permite la discriminación de clases. Clasifican objetos reales según ciertas características, tipologías o nombres, dándoles un nombre o símbolo. Los objetos se clasifican con relación a una igualdad o equivalencia de un aspecto o característica.

- La escala ordinal o jerárquica. Establece, además, una ordenación entre los distintos elementos con relación a una característica, posibilitando hacer comparaciones entre los mismos.

- La escala de intervalos o de distancia iguales. Impone regularidad en el intervalo de clases, aún con carencia de la fijación del cero de forma unívoca. Representan un nivel de medición más preciso que los anteriores: no solo establece un orden en las posiciones relativas de los objetos o individuos, sino que se mide también la distancia entre los intervalos.

- La escala de ratio o proporcional. Añade a la anterior la posesión del cero de for- 
ma unívoca. Escala de ratio: además de lo dicho para la escala de intervalo, tenemos un cero de referencia (ejemplo.: longitud de código: número de líneas de código).

La aplicación de múltiples escalas de medición en Contabilidad, conduce al profesor
Cañibano (1979) a afirmar que «el método contable maneja una escala múltiple o multidimensional, ya que los datos sometidos al mismo son medidos de acuerdo con varias escalas cada una de las cuales expresa sus resultados en una distinta dimensión».

\begin{tabular}{|c|c|c|c|}
\hline ESCALA & $\begin{array}{l}\text { OPERACIONES } \\
\text { EMPÍRICAS BÁSICAS }\end{array}$ & $\begin{array}{c}\text { TIPO DE ESTRUCTURA } \\
\text { MATEMÁTICA }\end{array}$ & EJEMPLOS CONTABLES \\
\hline NOMINAL & $\begin{array}{l}\text { Determinación de } \\
\text { igualdad }\end{array}$ & $\begin{array}{l}\text { Permutación } x^{\prime}=f(x) \text { donde } f(x) \\
\text { significa cualquier sustitución } \\
\text { biunívoca. }\end{array}$ & Codificación de cuentas. \\
\hline ORDINAL & $\begin{array}{l}\text { Determinación de } \\
\text { mayor a menor }\end{array}$ & $\begin{array}{l}\text { lsotónico } x=f(x) \text { donde } f(x) \text { significa } \\
\text { cualquier función monótona } \\
\text { creciente. }\end{array}$ & $\begin{array}{l}\text { Clasificación de los clientes por } \\
\text { categorías. }\end{array}$ \\
\hline $\begin{array}{l}\text { POR } \\
\text { INTERVALOS }\end{array}$ & $\begin{array}{l}\text { Determinación de los } \\
\text { intervalos o de las } \\
\text { diferencias }\end{array}$ & $\begin{array}{l}\text { Lineal } 0 \text { afín } x^{\prime}=a x+b \\
\text { a } 0\end{array}$ & Cálculo de costos estándar. \\
\hline $\begin{array}{l}\text { POR } \\
\text { COCIENTES }\end{array}$ & $\begin{array}{l}\text { Determinación de } \\
\text { la igualdad de los } \\
\text { cocientes }\end{array}$ & $\begin{array}{l}\text { Similar } x=c \\
\text { C } 0\end{array}$ & $\begin{array}{l}\text { Conversión de las distintas } \\
\text { monedas en una común cuando } \\
\text { se consolidad los estados } \\
\text { financieros de un grupo } \\
\text { multinacional de empresas. }\end{array}$ \\
\hline
\end{tabular}

Queremos resaltar que el carácter multidimencional de la medición contable, no proviene solo de la diversidad de escalas utilizadas, sino que dentro de una misma escala puede utilizarse conjuntamente distintas unidades de cuentas. Este es el caso planteado por Ijiri, quien manejando únicamente la escala de medición por cociente, efectúa un tratamiento contable multidimensional de una cierta estructura económico-financiera inicial y una serie de transacciones posteriores (Ijiri, 1971; 110-115).

Actualmente, la metrología contable es una teoría de la medición de los activos intangibles cuyas siglas son CONAIN, tiene como fundamento teórico a la lógica difusa. Su sistema axiomático es consecuencia de los estudios epistemológicos y el resultado de la filosofía de la mente. Dichos axiomas están presentados en términos formales no interpretados.

La lógica difusa (Fuzzy Logic) ha surgido como una herramienta para el manejo eficiente de sistemas en situaciones borrosas o ambiguas. La lógica fuzzy es básicamente una lógica multievaluada que permite valores intermedios para poder definir evaluaciones convencionales como sí/no, verdadero/ falso, negro/blanco, etc. Las nociones como «más bien caliente» o "poco frío» pueden formularse matemáticamente y ser procesados por computadoras. De esta forma, se ha realizado un intento de aplicar una forma más humana de pensar en la programación de computadoras. La lógica borrosa se inició en 1965, por Lotfi A. Zadeh, profesor de ciencia de computadoras en la Universidad de California en Berkeley.

\section{La valoración contable}

La función de medición dará como resultado una serie de magnitudes de carácter heterogéneo que necesariamente deberán ser homogeneizadas, es decir, deberán referirse a un patrón de medida común. Este patrón suele ser la unidad monetaria, aun cuando podría utilizarse cualquier tipo de

\section{QUIPURAMAYOC}


unidad. El profesor Requena (1977) distingue en el proceso de medición monetaria de los aspectos tangibles, tres momentos consecutivos:

- Medición física.

- Fijación del correspondiente parámetro de conversión, que se conoce como precio de un determinado elemento y representa, por tanto, el valor del mismo.

- Expresión monetaria de las unidades físicas obtenidas en la medición a través de la aplicación del coeficiente obtenido en la segunda fase.

Sin embargo, habiéndose añadido, la valorización de las fuentes de conocimientos de los intangibles, para la homogeneización de estos, debemos considerar qué posibilidad hay de valorarlos tomando en cuenta los siguientes modelos:

- Modelos subjetivistas. Toman como premisa que el valor de mercado de un activo intangible puede ser expresado como el valor presente de los futuros beneficios económicos que se derivarán de la propiedad de este. Existen tres aproximaciones diferentes para el enfoque de ingresos:

La primera es el enfoque denominado "With-and-without", que tiene como primer paso la valoración de la totalidad de la empresa con todos sus activos (tangibles e intangibles), para luego valorar la empresa excluyendo la rentabilidad asociada con el activo intangible a ser valorado. La diferencia de ambos valores es atribuida al valor del intangible.

La segunda aproximación corresponde al Enfoque de Ahorro por Royalty (Relief from Royalty Approach), que valora el intangible a partir de la estimación de los flujos proyectados de ahorro de costos, debido a no tener que pagar por la licencia de este, es decir, el valor del intangible se mide mediante el ahorro de costos en que incurre el propietario debido a que no debe pagar ningún royalty para utilizar este activo.

La tercera aproximación corresponde al Enfoque por Beneficios Residuales (Exceso Earnings Approach), que se basa en que los retornos económicos, más allá de los retornos atribuibles a activos tangibles, se pueden derivar de ciertos activos intangibles del negocio. Para determinar estos retornos, en primer lugar, se debe proyectar el nivel de ingreso normal de la empresa; luego, se deben calcular los cargos pro forma para los retornos económicos relacionados a los activos tangibles empleados (capital de trabajo y activos fijos), y finalmente, los cargos pro forma para los retornos relacionados a otros activos intangibles. Por último, las utilidades residuales deben ser descontadas a la tasa de descuento ajustada por riesgo.

- Modelos Convencionalistas. Emplean el modelo de Costos de Reposición; tal como lo indica su nombre, se basa en la estimación del dinero requerido para reemplazar la capacidad de servicio del bien. Esto se sustenta en que el precio de la nueva propiedad debe ser proporcional al valor económico del servicio que la propiedad puede ofrecer, tomando en cuenta la depreciación por obsolescencia.

Si el costo de reposición está influenciado por el mercado, significa que el costo relevante es el monto mayor que el mercado está dispuesto a pagar por el intangible. Este no es necesariamente el costo histórico requerido para la creación de este intangible, sino que es el costo económico de este el que se basa en los recursos requeridos a ser utilizados para crear el activo.

- Modelos Objetivistas. Finalmente, el modelo de Mercado es la medida más directa para cuantificar el valor presente de 
beneficios futuros, mediante el análisis del intercambio de bienes comparables en un periodo determinado; para lo cual es indispensable la existencia de un mercado activo, y usuarios plenamente informados.

Esto nos permite concluir en la importancia de considerar los distintos activos intangibles como potencial fuente de ingresos, gracias a sus varias formas de explotación, para lo cual se vuelve imprescindible el valorarlos económicamente, mediante alguno de los métodos ya descritos, cuya elección dependerá del activo a ser valorado y de la información disponible que se posea.

\section{La representación y coordinación contable}

La Contabilidad, una vez realizadas las funciones de captación, medición y valoración de las diferentes magnitudes que constituyen la realidad objeto de estudio, procede la representación de la fenomenología captada.

La complejidad de la realidad objeto de la ciencia contable imposibilita o dificulta el conocimiento directo de sus diferentes estados, y por tanto, el análisis prospectivo y retrospectivo de los mismos. Ante tales circunstancias, la Contabilidad se ve obligada a acudir a la utilización de entes representativos con la única finalidad de transmitir su imagen con la fidelidad necesaria, a través de diferentes métodos, que descansan sobre el principio de la dualidad, que, de alguna forma, ya se hallaba implícito en la partida doble de Pacciolo.

Entre las diferentes formas en que la Contabilidad puede conseguir sus fines propuestos, exponentes de los referidos métodos de representación, se encuentra la Contabilidad convencional —que engloba a la denomina- da Contabilidad clásica, a la Contabilidad matricial y a la Contabilidad vectorial-, la Contabilidad funcional y la Contabilidad sagital o por net-work (Requena, 1988).

Para la Contabilidad del conocimiento, esta representación se realizaría utilizando herramientas modernas de control como son el Balanced Scorecard, projet, etc.

\section{E. La agregación contable}

Realizadas las funciones de captación, medición, valoración y representación, es necesario un proceso mediante el cual, y a partir de diversas agregaciones o sumas, se obtengan unos estados sintéticos, que en la literatura contable recibe la denominación de proceso de agregación contable, en aras de la consecución de una visión más sintética y ordenada de la realidad, que posibilite extraer ciertas conclusiones.

El primer estadio del proceso agregativo, lo constituye la cuenta; ya que la contabilidad a través de esta, sintetiza y representa la interacción de la transacción económica, de una manera homogénea formando subsistemas de agregación objetiva -o de magnitudes homogéneas- como (financiación, inversión, producción de costos, etc.). El siguiente estadio sería las síntesis periódica (día, mes, etc.) generado por la partida doble que da origen al Balance. Asimismo, hay una agregación subjetiva que es producto de una síntesis obtenida de un sistema contable integral, en la cual se han agrupado transacciones de naturaleza distinta pero que hace referencia un mismo ente. En otro orden de ideas, $y$ ante el hecho de la vinculación de un gran número de empresas en las economías actuales, la Contabilidad desarrolla un cuerpo teórico que le permite seguir representando lo más exacta y objetivamente posible, esa realidad, que se ha venido a denominar 
Consolidación, Agregación o Integración de Estados Contables ${ }^{17}$.

Entonces, estamos asistiendo a la agregación de los estados económicos financieros de una empresa o un conjunto de empresas que son jurídicamente independientes pero que desde una perspectiva económica, están integradas en un mismo grupo de decisión. La contabilidad del conocimiento debe considerar esta situación para cuantificar financieramente los resultados de las estrategias y, con relación a ello, presentar los componentes del activo intangible no visto por la contabilidad tradicional.

\section{F. La interpretación contable}

Tomando como punto de partida la compleja y heterogénea realidad objeto de estudio por la Contabilidad, se llega a una síntesis coherente de la misma mediante una serie de funciones, que con anterioridad hemos comentado, con un procedimiento eminentemente inductivo. Sin embargo, no será completo el método operativo contable si este no desarrollara, además, un conjunto de operaciones con las que sea posible extraer conclusiones válidas y fiables acerca de la compleja fenomenología captada. En definitiva, se trata de poner de manifiesto la información obtenida sobre el estado y evolución de la unidad económica analizada de manera que tal interpretación sirva de base para la adopción de decisiones.

El profesor Rocafort (1983) piensa que dicho proceso que se caracteriza por su aspecto deductivo, permite "conocer las relaciones de causa a efecto que han motivado la situación presente, distinguir aquellos aspectos que han sido positivos, y que conviene reforzar, de aquellos otros que tienen significación negativa, que conviene controlar, anular o cambiar. Corresponde, por tanto, establecer un tratamiento que nos permita dar un pronóstico de curación o mejoramiento de la salud empresarial».

Esta función de interpretación, por parte de la doctrina recibe la denominación de Análisis Contable. A juicio del profesor Cañibano (1996), consiste «en el estudio comparativo de la información contenida en los diferentes estados contables, con el fin de extraer conclusiones sobre la situación económica-financiera de la entidad a la que pertenecen, haciendo uso de aquellos instrumentos técnicos que facilitan las antedichas comparaciones».

\section{G. La información contable}

Además de la dirección de la empresa, los usuarios externos son fundamentalmente los destinatarios de la Contabilidad Financiera, y constituyen un grupo con cierto grado de heterogeneidad y, por tanto, con objetivos particulares diferentes.

La empresa recibe unos recursos financieros de personas o entidades que, en la mayoría de las ocasiones no tiene contacto directo con la misma, ya revistan la denominación de acreedores o la de titulares de participaciones del capital social. Pero, aparte de estos, puede haber otros grupos e instituciones sociales interesados en la marcha o evolución de la empresa en cuestión, por las implicaciones de diversa naturaleza que la misma tiene con su entorno social. Todos estarán interesados en mayor o menor medida, en la marcha de la empresa, según las repercusiones que para cada uno de ellos tenga dicha sociedad, por

17 Un estudio en profundidad del tema de la consolidación de los estados contables puede encontrarse, entre otras, en las obras de: Álvarez Melcó N. (1978b), Cañibano y Cea (1972), Fernández Peña (1977), Cubillo Valverde (1983), Aragón Rodríguez (1994). 
lo que tendrán obviamente unas determinadas necesidades de información.

En este sentido, pudiera plantearse qué derecho asiste a los agentes económicos no vinculados a la gestión de la mencionada empresa para adentrarse en las interioridades de la misma. Con independencia de razones de seguridad, pensamos que en un gran número de circunstancias, esa información se da o deberá darse debido a que la empresa no es un agente aislado del mundo: ella, al igual que cualquier persona individual o social, está interrelacionada con su entorno y sin él no tendría razón de existir, de ahí la cada vez mayor exigencia de la misma para aquellos grupos sociales que la justifican.

Las necesidades de los usuarios determinan cuáles son los objetivos de la información, de ahí que este deba responder a unos principios contables, previamente diseñados, al objeto de que la misma pueda satisfacer suficientemente a sus receptores de información.

Las características cualitativas que debe reunir la información contable, son las siguientes:

- Identificabilidad. Los estados contables periódicos se refieren a sujetos económicos perfectamente definidos en cuanto a su área de actividad económica y a momentos o intervalos temporales perfectamente identificados.

- Oportunidad. La información contable debe ofrecerse a los decidores económicos en tiempo oportuno, ya que unos datos presentados a destiempo se convierten en inútiles para la aplicación a la que están ordenados.

- Claridad. La información contable debe ser mostrada en términos claros y asequibles, con el fin de asegurar, dentro de lo posible, la adecuada utilización de la misma por parte de sus diferentes destinatarios, los cuales no tienen que ser especialistas en materia contable.
- Relevancia. La información ha de poseer una utilidad notoria, potencial o real, para los fines perseguidos por los diferentes destinatarios de los estados contables; igualmente, ha de ser completa, para que se pueda alcanzar un conocimiento suficiente de los hechos que se tratan de relevar, por lo que se deben declarar todos los datos pertinentes e informaciones adicionales necesarias para el proceso de adopción de decisiones.

- Razonabilidad. La información contable no puede alcanzar en todos los casos una exactitud completa sobre los sucesos de la actividad económica que trata de dar a conocer, por lo que debe perseguir una aproximación razonable de los mismos. La mayoría de los sucesos económicos se prestan a diversas conjeturas, no son medibles con entera precisión, dependen de sucesos aleatorios, etc.

- Economicidad. La información contable es útil para el proceso de adopción de decisiones, pero, al mismo tiempo, su obtención ocasiona costos, por lo que, para su elaboración debe tomarse en cuenta el criterio beneficio-costo.

- Imparcialidad. La información contenida en los estados contables periódicos ha de elaborarse con la intención de que sea absolutamente neutral e imparcial; es decir, que no tergiverse o distorsione los datos en favor de ciertos destinatarios y en perjuicio de otros.

- Objetividad. La información contable ha de elaborarse utilizando un mecanismo de procesamiento que impida al máximo la introducción de criterios subjetivos por parte de los responsables del proceso. La información contable posee un grado de objetividad suficiente cuando varios procesadores de los mismos hechos contables, dentro de un mismo sistema de informa- 
ción, y aplicando las mismas reglas, pueden llegar a unos datos análogos entre ellos.

- Verificabilidad. La información contenida en los estados contables debe ser susceptible de control y revisión, interna y externa. La verificabilidad interna depende esencialmente de las normas de control interno que, efectivamente, regulen las diferentes operaciones que desarrolla la empresa y el propio sistema de procesamiento de la información contable. La verificabilidad externa representa la propiedad de la información de ser sometida a comprobación a través de pruebas pertinentes fuera del sistema de procesamiento, y representa una garantía necesaria para sus usuarios respecto al cumplimiento de los requisitos que deben ser exigidos a la información y a la correcta aplicación de los principios contables que sirven de base para su elaboración; esta garantía es máxima cuando la revisión es realizada por profesionales especializados e independientes de la empresa.

\section{La contabilidad del conocimiento}

La contabilidad del conocimiento surge como respuesta a los problemas derivados de la contabilidad tradicional al no poder generar información para administrar el capital intelectual (Gestión del conocimiento).

- El conocimiento es personal, en el sentido de que se origina y reside en las personas, que lo asimilan como resultado de su propia experiencia (es decir, de su propio "hacer», ya sea físico o intelectual) y lo incorporan a su acervo personal estando «convencidas» de su significado e implicaciones, articulándolo como un todo organizado que da estructura y significado a sus distintas «piezas».
- Su utilización, que puede repetirse sin que el conocimiento «se consuma» como ocurre con otros bienes físicos, permite «entender» los fenómenos que las personas perciben (cada una "a su manera», de acuerdo precisamente con lo que su conocimiento implica en un momento determinado), y también "evaluarlos», en el sentido de juzgar la bondad o conveniencia de los mismos para cada una en cada momento.

- Sirve de guía para la acción de las personas, en el sentido de decidir qué hacer en cada momento, porque esa acción tiene, en general, por objetivo mejorar las consecuencias, para cada individuo, de los fenómenos percibidos (incluso cambiándolos si es posible).

Estas características convierten al conocimiento, cuando en él se basa la oferta de una empresa en el mercado, en un cimiento sólido para el desarrollo de sus ventajas competitivas. En efecto, en la medida en que es el resultado de la acumulación de experiencias de personas, su imitación es complicada, a menos que existan representaciones precisas que permitan su transmisión a otras personas efectiva y eficientemente.

En conclusión, para dar lugar a la contabilidad del conocimiento, primero debemos concebir al conocimiento como un recurso o activo de la empresa que constituye un alto valor y fuente de riqueza que debe administrarse mediante procesos organizacionales, por su reconocimiento como factor crucial de mejora de la producción y servicios al cliente, que mejoran el desempeño de la organización, dinamizándola y generando o agregando valor en las operaciones que esta realiza. En segundo lugar, reconocer que estos son intangibles que tienen características específicas conocidas 
como Capital Intelectual, las mismas que son reconocidas en el IAS 38, y específicamente en el Estudio 7 del IFAC titulado «La medición y gerenciamiento del Capital Intelectual: una introducción», que reconoce en los modelos desarrollados por la doctrina internacional que el capital intelectual se puede conceptuar como la suma de tres componentes que se interrelacionan para la formación del valor:

a) Capital Humano. Formado por las habilidades, educación, calificación personal, conocimientos relativos al trabajo, tasa ocupacional, tasa psicometría, capacidades relacionadas con el trabajo, empuje empresarial, habilidades de acción y reacción para las innovaciones, flexibilidad, etc.

b) Capital clientela. Formado por las marcas de fábrica, clientes, la lealtad de los clientes, los nombres de la empresa, la acumulación de pedidos, los canales de distribución, las colaboraciones de negocios, los acuerdos de licencias, los contratos favorables, los acuerdos de franchising, etc.

c) Capital Organizacional (estructural). Dividido a su vez en:

- Propiedad intelectual. Conformado por las patentes, derechos de edición, derechos de diseño, fórmulas secretas, marcas comerciales y marcas de servicios.

- Infraestructura de activos. Donde se considera la filosofía de gerenciamiento, la cultura corporativa, el proceso de gerenciamiento, los sistemas de información, los sistemas de redes de trabajo y las relaciones financieras.

Hasta ahora, se ha intentado establecer qué elementos integran esta expresión que parece haberse puesto de moda en los últimos tiempos: "Capital Intelectual». Sin duda, se trata de intangibles imprescindibles para las creación de valor en las empresas y que le otorgan a las mismas, ventajas comparativas en relación a otras. En base a lo expuesto, se establecen los siguientes componentes del capital intelectual:

A. Activos de mercado. Comprenden las marcas, denominación social de la empresa, fidelidad de la clientela, reserva de pedidos, canales de distribución, licencias y franquicias. En definitiva, son elementos que proporcionan a la empresa una ventaja competitiva en el mercado.

B. Activos de propiedad intelectual. Incluyen elementos como conocer a la empresa, secretos de fabricación, derechos de autor, patentes, derechos de diseño y marcas de fábricas y servicios.

C. Activos de infraestructuras. Comprenden elementos que definen la forma de trabajo en la organización: filosofía de la gestión, cultura corporativa, procesos de gestión, tecnología de la información, sistemas de interconexión y relaciones financieras.

C. Activos centrados en el individuo. Incluyen elementos tales como el nivel de estudios alcanzado, calificaciones profesionales, conocimientos técnicos, psicometría asociados con el trabajo.

Estos elementos, a diferencia de los activos de mercado, de propiedad intelectual y de infraestructura, no pueden ser de propiedad de la empresa.

Por lo tanto, son activos intangibles todo aquello que la organización utiliza para generar valor tales como: las capacidades que se generan en la organización cuando los recursos empiezan a trabajar en grupo y coordinadamente. Para ello, la contabilidad del conocimiento debe explicar y sistematizar los procesos asociados a 
su creación, recolección, organización, difusión, uso y explotación, transformando el conocimiento personal en corporativo que debe ser distribuido ampliamente en toda la organización y aplicado de manera apropiada. Entonces, hoy el problema radica en disponer de medidas comprensibles que sean útiles para su reconocimiento, valorización y revelación. En el siguiente cuadro resumimos este tipo de activos:

\begin{tabular}{|c|c|c|c|c|}
\hline \multirow{3}{*}{$\begin{array}{c}\text { ACTIVOS } \\
\text { INTANGIBLES VISIBLES }\end{array}$} & \multicolumn{2}{|c|}{ TIPOS } & \multirow{3}{*}{$\begin{array}{c}\text { DISPOSICIONES } \\
\text { IASC } \\
\text { FASB } \\
\text { PCGA } \\
\text { AECA } \\
\text { ICAC }\end{array}$} & \multirow{3}{*}{\begin{tabular}{l}
$\quad$ TRATAMIENTO \\
\multicolumn{1}{c}{ CONTABLE } \\
analizar partidas \\
por partidas \\
discrepancias y \\
normativas
\end{tabular}} \\
\hline & $\begin{array}{l}\text { identificables y } \\
\text { controlables }\end{array}$ & $\begin{array}{l}\text { Marcas, gastos de } \\
I+D\end{array}$ & & \\
\hline & $\begin{array}{l}\text { no identificables } \\
\text { y controlables }\end{array}$ & Fondo de Comercio & & \\
\hline $\begin{array}{l}\text { ACTIVOS } \\
\text { INTANGIBLES } \\
\text { OCULTOS }\end{array}$ & capital intelectual & $\begin{array}{c}\text { Humano } \\
+ \\
\text { Estructural } \\
+ \\
\text { Clientela }\end{array}$ & Sin & gulación \\
\hline
\end{tabular}

\subsection{Modelos de medición y administración del capital intelectual}

Los responsables de los negocios y aquellos que buscan invertir en ellos, necesitan información relacionada con el valor de los activos intangibles, referido tanto al conocimiento como aquellos inherentes a la relación de la organización con su entorno y a la utilización eficiente de su estructura operativa. Es en esta necesidad que se plantean los modelos de medición y control del capital intelectual que buscan resolver el valor real de los activos que no se registran contablemente y que usualmente son llamados "fondo de comercio», "valor agregado de mercado», "conocimiento de la empresa», "capital intelectual», ya que el valor real de una empresa no coincide con lo que dicen sus balances y registros contables.

Desde la década del setenta, y con mucha más fuerza a partir del último quinquenio del siglo pasado, han surgido sistemas de control que, en su proceso integracional, no se contentan con desarrollar indicadores financieros, sino que avanzan sobre elementos de la empresa que no son tomados en cuenta por la contabilidad tradicional. Estos sistemas, conocidos entre otros son:

a) El Balanced Scorecard. Creado por Rober Kaplan y David Norton. Manifiestan que los activos no reconocidos contablemente, entre los que se encuentran los referentes al capital intelectual deben ser medidos a través de indicadores, ya que «lo que no se mide no se gestiona» y siendo los activos intangibles un factor importante de la gestión empresarial, es comprensible su estudio y evaluación bajo cuatro perspectivas planteadas:

- Perspectiva Financiera. Los indicadores financieros tales como: la rentabilidad sobre la inversión, flujos de caja, análisis de la rentabilidad de clientes y productos, gestión de riesgo entre otros deben ser complementados con otros asociados a la realidad empresarial.

- Perspectiva del cliente. Debe identificar los valores relacionados con los clientes que incrementan la capacidad competitiva de la empresa. Para ello debemos realizar un análisis del valor y calidad de éstos en el segmento de mercado objetivo. 
- Perspectiva de los procesos internos. Analiza cómo se adecúan los procesos de la empresa para lograr la satisfacción del cliente y conseguir con ello los niveles de rendimiento financiero planificados. En estos procesos internos, distinguimos tres tipos de procesos: de innovación, de operaciones y de servicios postventa.
- Perspectiva del aprendizaje y crecimiento. Presenta al conjunto de indicadores que constituyen los activos que dotan a la organización de la habilidad para mejorar y aprender, tales como: capacidad y competencia de personas, sistemas de información, cultura-clima-motivación para el aprendizaje y la acción.

BALANCED SCORECAD

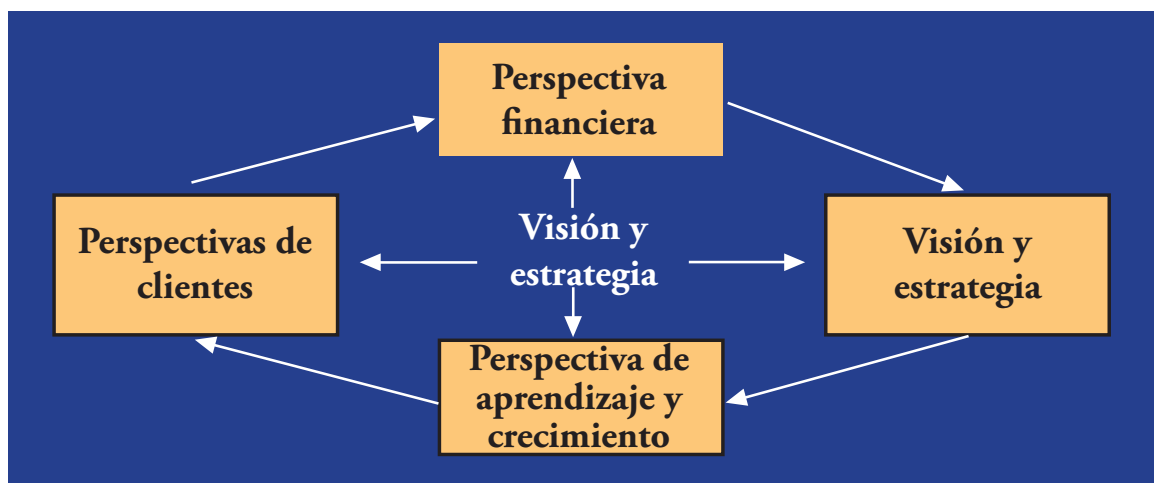

Fuente: Kaplan y Norton (1996).

b) Modelo de valoración de negocios. Parte de la misma base e indica que se debe ir más allá de los números tradicionales y ayudar a implementar la estrategia estructurado en tres niveles:

- Cualidad de liderazgo $=$ Adminis tración

- Creación de valor $=$ Operaciones + desempeño

- Generación de ingresos $=$ Negocio central + Mercado + Competencia

c) Valor Económico Agregado (EVA). Es un indicador de desempeño financiero que mide el valor económico creado para los accionistas por una empresa en un periodo determinado. Surge cuando la empresa genera ingresos superiores a sus costos de operación más el costo del capital utilizado (tanto propio como ajeno), determinando el valor agregado que recibirán los accionistas. Su utilización logra que los responsables de la administración y cada uno de los niveles de la empresa adquiera conciencia de las decisiones para crear y destruir valor, formando una cultura de creación de valor. Entonces, de acuerdo con este índice, si la rentabilidad/retorno sobre el capital de la empresa sobrepasa sus costos de capital, se está creando verdadero valor para los accionistas. Este índice mezcla tres elementos importantes:

- El flujo de efectivo.

- El efectivo medido durante un período (duración del crecimiento del valor).

- Riesgo conocido como costo de capital.

d) Valor de Mercado Agregado (MVA). Es un indicador de desempeño financiero que puede ser utilizado como herramienta administrativa para el mejoramiento de la compañía. Es igual al valor presente de todos los EVA futuros. 
e) Análisis del Valor de Accionistas (SVA). Es un modelo económico para la evaluación estratégica y mide el impacto económico de cada estrategia sobre el valor del negocio. Esta medición combina el flujo de efectivo, el efectivo medido durante un periodo y el costo de capital (riesgo).

f) Círculo aprendizaje-conocimiento-valor. Basándonos en que el conocimiento es el material fundamental de la construcción de una organización surge la necesidad de convertir este conocimiento en dinero haciendo la: liquidación del conocimiento. Para poder medirlo es necesario traducirlo al lenguaje de Bits para que al compararlo con el valor pagado se obtenga el precio por Bit.

g) Auditoría de Procesos de Negocio (APN). Evalúa el retorno que una organización deriva a partir de sus procesos y el conocimiento inserto en ellos, evaluando objetivamente los procesos de manera simultánea al Ongoing (en marcha).

\subsection{Propuesta técnica y científica de la contabilidad del conocimiento}

Identificación del capital intelectual y presentación de un nuevo modelo para su aplicación en la contabilidad del conocimiento.

Siendo la Contabilidad el lenguaje de los negocios y dada la evolución de estos en las últimas décadas, nos queda muy claro que la contabilidad debe de cambiar, ya que algunos elementos definitivamente pertenecen al pasado y hoy ya no sirven, dadas las circunstancias actuales de los negocios y de las organizaciones. Es obvio que los negocios cambiaron, actualmente son múltiples y variados, veloces casi frenéticos y complejos, es decir, ya no son solamente un deudor y un acreedor, tal como lo indicamos en párrafos anteriores. En términos económicos ya no se está centrado solo en el intercambio comercial o en la producción, hoy giran en la generación del valor agregado en sus servicios, información y conocimiento.

Es decir del modelo tradicional estático de la contabilidad tradicional:

\section{ACTIVO}

\section{PASIVO}

PATRIMONIO

NETO

Debemos de pasar a un modelo sistémico integral, proactivo y futurista de la contabilidad que nos guíe no solo en nuestra manera de pensar, sino en la ubicación, localización, funciones y resultados del capital intelectual que manejen las empresas para su posterior presentación en los estados financieros que incluya esta. Para ello, debemos de presentar el modelo sugerido de la nueva visión de la contabilidad:

\section{\begin{tabular}{c|c|c|c|c|}
\hline POTENCIALIDAD & + & PERFORMANCE & $\begin{array}{c}\text { POSICIONAMIENTO } \\
\text { EMPRESARIAL }\end{array}$
\end{tabular}}

Al replantear la fórmula contable tradicional, fundamentamos nuestra teoría en la «perspectiva contable de justificar la dife- rencia entre el valor de mercado y el valor contable», en estas tres variables. Para ello, definiremos, analizaremos el contenido y 
significado de cada una de éstas con la finalidad de llegar a un entendimiento del proceso de valorización de la empresa que incluya el capital intelectual.

- La potencialidad. La potencialidad de los negocios dependen de su estructura organizacional o capacidad operativa que está compuesta por los activos que mantiene la empresa como inversión (vida útil para proyectar el negocio al futuro) y los pasivos o capitales financieros que financian la misma. Esta variable estática es producto de la contabilidad tradicional que al asociarse con los clientes o mercado, puede medir sus resultados financieros a través del estado de ganancias y pérdidas.

- La performance. Significa «lo que se debe hacer», esta variable la fundamentamos en la «teoría de los recursos y capacidades» que tiene la empresa para hacer una gestión o desempeño óptimo. En efecto, ante entornos turbulentos, con incertidumbre, complejidad, competencia global, acortamiento del ciclo de vida de los productos, cambios rápidos en los gustos y las necesidades de los consumidores, etc., la empresa tiene dificultades para plantearse qué necesidades quiere satisfacer, por lo que, puede preguntarse alternativamente, acerca de qué necesidades puede satisfacer. En este último caso, la orientación externa no puede ser el único fundamento de la estrategia empresarial, sino que es preciso recurrir al análisis de los recursos y capacidades disponibles para poner en marcha una estrategia.

Bajo el criterio definido en el párrafo anterior, para que funcione esta variable se debe partir seleccionando una estrategia que explote los recursos y capacidades de la empresa, asegurando el uso total de ellos para llegar al beneficio óptimo planificado. Es decir, esta variable dinamiza la potencialidad del negocio y determina como resultado el valor agregado de la organización hacia sus clientes. Por consiguiente, si hablamos de la organización y su actuación en los diferentes niveles ya sea definiendo estrategias y cumpliendo los objetivos corporativos estimados, consideramos que es en esta variable que se ubica el capital intelectual.

La performance debe ser evaluada en:

a) El capital humano (recursos humanos), el capital estructural (procesos, tecnología) y el capital relacional (los clientes).

b) La administración de la información dentro de la organización.

c) La participación del conocimiento como actividad y útil para las necesidades estratégicas de la empresa.

d) El aprendizaje continúo.

Estos elementos de la performance solo tienen valor al combinarse con la inversión de la empresa u otros activos netos que denominamos potencialidad. Presentamos seguidamente una matriz que nos ayudará a conocer las causas que son determinantes en el desempeño de la empresa, la misma que según nuestro modelo sugerido al ser evaluado determinará una performance positiva o negativa.

Cuando la performance es positiva, nuestra propuesta es reconocer los gastos contabilizados como parte de la inversión al haberse reconocido y validado en el desempeño de la empresa los activos intangibles provenientes de competencias personales, estructura interna y estructura externa.

- Posicionamiento Empresarial. O valor de la empresa que debe ser cuantificado 


\begin{tabular}{|c|c|c|}
\hline EFECTO & CAUSA & CAUSA \\
\hline \multirow{4}{*}{$\begin{array}{l}\text { DESEMPEÑO DE } \\
\text { LA EMPRESA }\end{array}$} & $\begin{array}{l}\text { FACILITADORES que proveen dirección y naturaleza } \\
\text { para las acciones }\end{array}$ & $\begin{array}{l}\text { - Conocimiento } \\
\text { - Activos intelectuales }\end{array}$ \\
\hline & $\begin{array}{l}\text { FACILITADORES que proveen soporte para las } \\
\text { acciones }\end{array}$ & $\begin{array}{l}\text { - Capital de operación } \\
\text { - Relación con los clientes } \\
\text { - Información de primera clase }\end{array}$ \\
\hline & $\begin{array}{l}\text { DIRECCIONADORES proveen impulso para las } \\
\text { acciones }\end{array}$ & $\begin{array}{l}\text { - Motivación del personal } \\
\text { - Demandas de los clientes } \\
\text { - Requerimientos de los clientes }\end{array}$ \\
\hline & $\begin{array}{l}\text { MECANISMOS que hacen posible realizar las } \\
\text { acciones }\end{array}$ & $\begin{array}{l}\text { - Inversión de capital } \\
\text { - Infraestructura } \\
\text { - Tecnología } \\
\text { - Organización del trabajo } \\
\text { - Prácticas de la empresa } \\
\text { - Estructura de la empresa }\end{array}$ \\
\hline
\end{tabular}

continuamente ya que este es el resultado de las ventajas competitivas generadas por el capital intelectual que maneja la empresa. Esta variable puede ser medida a través de las finanzas modernas (método de descuento de flujos de efectivo futuro, de capitalización de ganancias, de múltiplo de ingresos, de valuación de activos netos, EVA, etc.) las mismas que deben ser consideradas para ajustar los estados financieros y reflejar la realidad financiera y económica para la toma de decisiones empresariales.

Con independencia del modelo que se utilice, en todo proceso de valoración, se necesitan fuentes de información lo más objetivas posibles acerca de la empresa, a fin de comparar con un eventual precio de mercado el valor que esta pueda tener para cada sujeto o usuario, ya sea en mercados organizados o en la negociación privada. Así pues, antes de aplicar cualquier método de valoración hará falta cuantificar una serie de circunstancias referentes a la empresa, unas más cuantitativas que otras y muchas de ellas, además, en forma prospectiva. Sin el trascendental proceso de cuantificación, cualquiera de las pretenciosas fórmulas de valoración de empresas o de acciones no deja de ser una entelequia (Posición de su perfección: Aristóteles).

La información y sus consecuencias son a un mismo tiempo origen y destino de la valoración, inputy output, es decir, elementos que posibilitan el proceso de valoración y que, a su vez, deben ser correctamente valorados. El primer aspecto conforma a la información como un factor productivo, que se sumaría a los clásicos capital y trabajo. «Las normas contables proponen que sean contabilizados como gastos del ejercicio». El segundo aspecto, la información como recurso productivo susceptible de valoración, es objeto de los más novedosos estudios y muestra una complicación tal que aún no ha sido resuelta de forma satisfactoria, la obtención «de alguna medida directa del valor de reposición de los intangibles...». A su vez, el cálculo que resulte de dicha resolución es un dato que ha de utilizarse sucesivamente como input de un nuevo proceso valorativo.

Una vez definida la información como input (recurso) y output (activo), procede una clasificación más exhaustiva, dentro del primer aspecto, según el origen o fuente (interna o externa), según el nivel de registro (contable o extracontable) y según el fenómeno a que se refiera. 


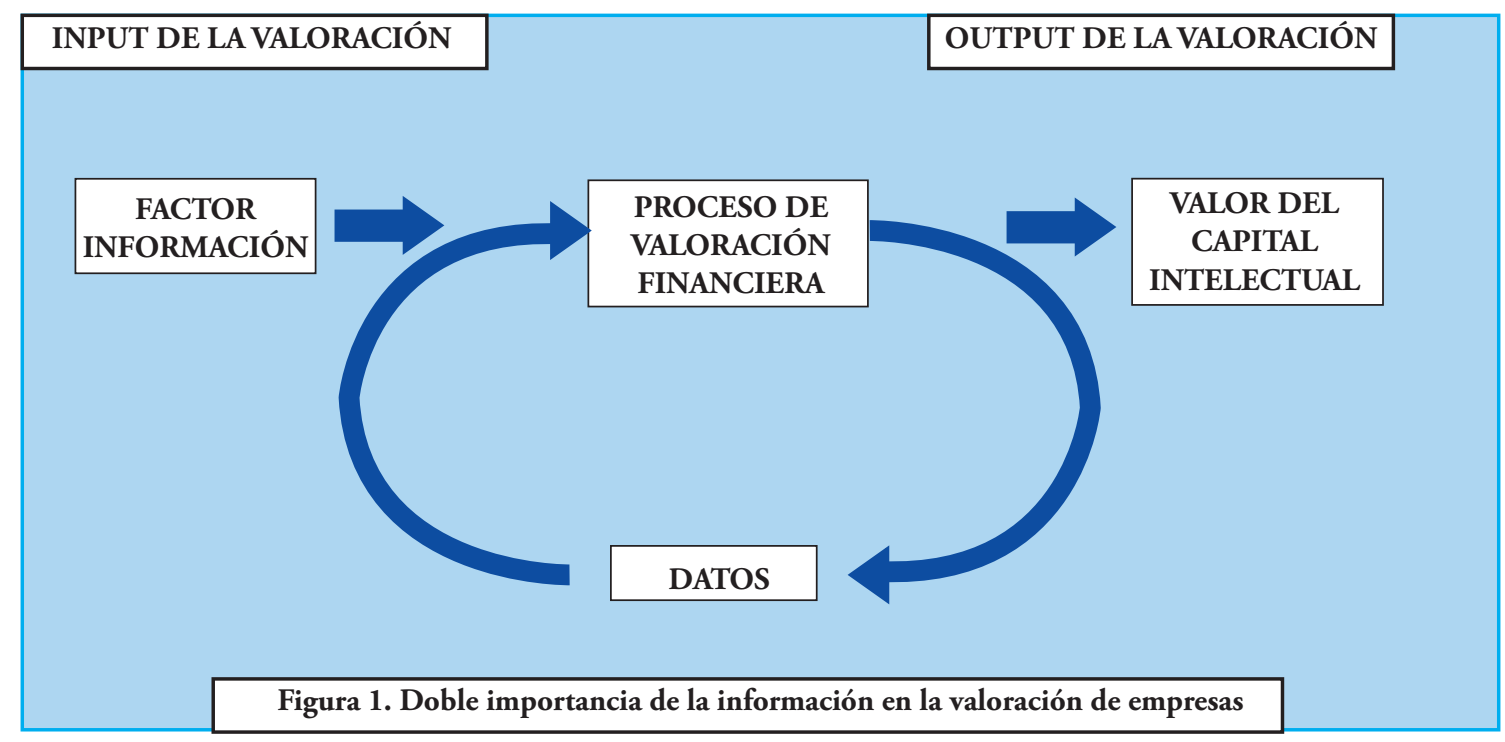

En conclusión, nuestra propuesta se sustenta en un nuevo enfoque contable a través del modelo sugerido para, posteriormente, medir en ella la performance o desempeño que tiene un efecto cuantitativo en la posición empresarial o valor de la empresa a una fecha determinada. De esta valorización empresarial sostenemos que se pueden determinar ajustes a los estados financieros tradicionales para llevarlos a valores económicos reales, además de detallarlos y explicarlos a través de la información complementaria. Es decir, este modelo sugerido debe integrar al balance tradicional el valor del capital intelectual.

\section{CONCLUSIONES}

1. Para comprender e iniciar el proceso de la metateorización de la contabilidad del conocimiento los profesionales y estudiantes de la Ciencia Contable, deben entender que la epistemología y la filosofía son las fuentes de análisis donde la razón y la experiencia encuentran su eficacia, este camino reflexivo servirá para que el contador no esté ajeno al en- tendimiento de la sistematización de la contabilidad del conocimiento.

2. La contabilidad debe concebir un modelo teorético que le permita insertarse en el sistema donde actúa, buscando converger con las teorías de las ciencias sociales y/o, específicamente, con las ciencias económicas empresariales, tales como: Economía y Administración, para dar origen a la teoría Convergente Tetradimensional de la Contabilidad del Conocimiento.

3. Para el proceso de metateorización contable, debemos considerar:

- La aplicación del Enfoque Sistémico Integrado como base fundamental para la modificación metodológica de la ciencia contable.

- Se debe determinar el contexto contable para construir puentes epistemológicos con otras ciencias, inicialmente podría ser concebida con las teorías económicas y administrativas.

- Se debe reconocer el nuevo Modelo Sistémico Integral y Holístico de la Contabilidad del Conocimiento, con sus variables: Potencialidad, performance y posicionamiento empresarial. 
- En esta primera etapa de la teorización de la contabilidad del conocimiento, se debe considerar la valorización empresarial para identificar el valor de los intangibles gestionados por la administración empresarial.

d. Todos los activos intangibles identificados en la organización empresarial, deben reducirse en la categoría "conocimiento» como resultado de la aplicación de los axiomas de la metrología contable denominada CONAIN, para ello debemos reconocer a la lógica difusa como el marco conceptual más poderoso para posibilitar la medición de los activos intangibles, su operacionalización debe ser el resultado de la valoración con el lenguaje natural de todos los recursos intangibles manejados por la empresa.

\section{REFERENCIAS}

BÉrtora, Héctor Raúl. Llave de negocio. Ediciones Macchi López, 1975.

Chávez, Osvaldo; Pahlen Acuña, Ricardo. Valor llave. Un enfoque actual. Ediciones Macchi, 1996

Boletín Asociación Española de ContabiLIDAD Y AUDITORÍA N.o 50. Entrevista a Leandro Cañibano. "Nuevos desafíos de la contabilidad ante el siglo XXI».

Sierra Fernández, Monserrat. «¿Hacia una nueva contabilidad? Contabilidad del Capital Intelectual». Boletín de la Asocia- ción Española de Contabilidad y Auditoría N.o 49.

InTERnATIONAL Federation OF ACCOUNTANTS. Estudio 7: The measurement and management of Intellectual Capital: An introduction. EE.UU., setiembre de 1998.

Cañibano, Leandro; García-Ayuso Covarsi, Manuel; SÁnchez, Paloma. La relevancia de los intangibles para la valoración y la gestión de empresas: revisión de literatura. Asociación Española de Contabilidad y Auditoría. Madrid, 1999.

Carazay, Cristina; Fernández, Analía; Nannini, María Susana; Suardi, Diana. "La llave de negocios en los Estados Contables». Revista Desarrollo y Gestión N.o 10 , julio de 2000.

Bueno Campos, Eduardo. «El capital intangible como clave estratégica en la competencia actual». Boletín de Estudios Económicos. Vol. LIII, N.o 164, agosto de 1998, pp. 207-229.

Caballer Mellado, V. Métodos de valoración de empresas. Pirámide, 1994.

Cabrera Monroy, Francisca y Galindo Lucas, Alfonso. «La importancia de la Información en la Valoración de Empresas». La Empresa del Siglo XXI: Finanzas, Tecnologías y Sistemas de Información (Volumen I), 2000, pp. 555-564. Diputación de Cádiz. Jerez de la Frontera. 